\title{
Externalizing behavior trajectories: The role of parenting, sibling relationships and child personality
}

\author{
Jean Christophe Meunier ${ }^{\mathrm{a}, *}$, Isabelle Roskam ${ }^{\mathrm{b}}$, Marie Stievenart ${ }^{\mathrm{b}}$, Gaëlle van de Moortele ${ }^{\mathrm{b}}$, \\ Dillon T. Browne ${ }^{a}$, Aarti Kumar ${ }^{\text {a }}$ \\ a Department of Human Development and Applied Psychology, University of Toronto, Toronto, Canada \\ ${ }^{\mathrm{b}}$ Department of Psychology, Université Catholique de Louvain, Louvain-la-Neuve, Belgium
}

\section{A R T I C L E I N F O}

Article history:

Received 29 July 2009

Received in revised form 26 August 2010

Accepted 23 September 2010

\section{Keywords:}

Parenting

Externalizing behavior

Parental self-efficacy

Child's personality

Sibling relationships

Developmental trajectories

\begin{abstract}
A B S T R A C T
Based on longitudinal multilevel modeling and using a multi-informant strategy, this study examines trajectories of externalizing problem behavior (EPB) in childhood as predicted by parental behavior (absolute level of parenting [ALP] and parental differential treatment [PDT]), parental self-efficacy (PSE), child personality and sibling relationships. Besides main effects, several interactions were tested. The effects of changes in parenting on changes in EPB were also examined. A total of 119 families from the French-speaking area of Belgium rearing a child (3- to 5-year-olds at the onset of the study) referred for EPB were studied. The effects of both level-of and changes-in mothers' ALP were partially confirmed, but for fathers, only ALP was predictive. There were some significant interactions between ALP and PDT for both parents. Mothers' PSE explained some variance in EPB, additional to that explained by the parenting measures. Some parenting by personality and by sibling relationship interactions were found.
\end{abstract}

(c) 2010 Elsevier Inc. All rights reserved.

\section{Introduction}

Externalizing problem behavior (EPB) is the most common and persistent form of childhood maladjustment (Campbell, 1995). In general, EPB is conceptualized as uninhibited behavior and related expressions of undersocialization in which negative emotions are directed against others and manifested as anger, aggression or frustration (Roeser, Eccles, \& Strobel, 1998). Despite general agreement about its conceptualization, there is evidence that the expression and frequency of EPB may change substantially as children develop (Larsson, Viding, Rijsdijk, \& Plomin, 2008). In this context, researchers have been strongly encouraged to study EPB from a developmental perspective (Burke, Pardini, \& Loeber, 2008). The study of the development of EPB in early childhood is of special interest because rapid behavioral changes are apparent during this period.

Because of its substantial and recognized influence, parenting has probably been the most widely studied correlate of child EPB over the last few decades (Rothbaum \& Weisz, 1994). However, from an ecological perspective which posits the child as nested in a complex network of interconnected systems (Bronfenbrenner, 1986), multiple sources, other than parenting, may contribute to EPB. Accumulating

\footnotetext{
* Corresponding author. Department of Human Development and Applied Psychology, University of Toronto, Bloor St. West, 252, Toronto, ON, Canada M5S 1V6.

E-mail addresses: jc.meunier@utoronto.ca, jean-christophe.meunier@uclouvain.be (J.C. Meunier)
}

evidence suggests that the family is a critical environment related to a broad range of important social and emotional behaviors and that environmental influences interact with children's personal attributes in the emergence of problematic behavior (Feinberg, Neiderhiser, Simmens, Reiss, \& Hetherington, 2000; Van Leeuwen, Mervielde, Braet, \& Bosmans, 2004). In this respect, some investigators are calling for including the siblings in the traditional parent-child dyadic approach (e.g., Boyle et al., 2004), whereas others encourage the combination of multiple risk factors associated with EBP in order to consider their respective-additive or multiplicative-contribution (e.g., Sameroff et al., 1997). Both approaches are intended to more fully understand the development of (problem) behavior in children.

Based on these assumptions and using a multilevel modeling (MLM) framework, the primary goal of the present study was to investigate the role of two components of parental behavior-absolute level of parenting (ALP) and parental differential treatment (PDT)and their change over time in predicting changes in children's EPB. While ALP represents parental behaviors which are uniquely directed toward a specific child, PDT includes the sibship by considering the extent to which children within the same family are differently treated by their parents. Although both ALP and PDT have been widely related to $\mathrm{EPB}$, studies combining these two approaches remain rare (e.g., Tamrouti-Makkink, Dubas, Gerris, \& van Aken, 2004). The secondary goal of the present study was to investigate the potential roles of parental self-efficacy, child personality and sibling relationships-along with ALP and PDT-as potential predictors of child EPB. Although main-effect type studies have repeatedly demonstrated 
links between these variables and child adjustment, these possible predictors have rarely been investigated simultaneously. As well as the exploration of additive effects on EPB, the present study investigates several moderating effects that have previously been demonstrated or suggested in the literature. Moderating effects are highly relevant given that several predictors (e.g., PDT) usually only account for a small percentage of the explained variance in adjustment measures (Turkheimer \& Waldron, 2000) and that studies of moderation effects have often been found to enhance the prediction of adjustment in childhood (e.g., Kowal, Kramer, Krull, \& Crick, 2002).

\section{Parental behavior and EPB trajectories}

The seminal work of Plomin and Daniels (1987) on parental influences has inspired increasing efforts to consider the ways in which a child is not only influenced by parental behavior that is shared by all the children in a family, but also by parental behavior that is not shared by siblings (Feinberg \& Hetherington, 2001). Research is increasingly focused on how parental differential treatment (PDT), rather than, or in addition to, the absolute level of parenting (ALP), may explain the influence parents have on their children. A large body of work has demonstrated links between ALP and child adjustment, with negative control behavior (e.g., parental coercion, inconsistent, conflictual and/or harsh discipline) and lack of supportive behavior (e.g., responsiveness, positive parenting) being consistently related to increased externalizing symptoms (Aunola \& Nurmi, 2005; Meunier, Roskam, \& Browne, in press). Similarly, differential treatment in negative control and supportive behavior has been associated with higher EPB in the disfavored child. However, in the rare studies investigating the roles of ALP and PDT simultaneously in predicting child EPB (e.g., Feinberg \& Hetherington, 2001; Tamrouti-Makkink et al., 2004), the additive effects of the two parenting measures have been inconsistently demonstrated. The inconsistencies have been attributed to differences in sample composition (referred vs. non-referred), child status (age, gender and birth order), sibling dyad composition (gender and age spacing) and the variables under investigation. Beyond simple additive effects, an ALP $\times$ PDT interaction in predicting EPB has been confirmed in several studies (e.g., Feinberg \& Hetherington, 2001). In the framework of social comparison theory, it has been suggested that, with high levels of parental negativity or low levels of parental warmth-which can be assumed to create stress and negative sibling relationships (Brody, Stoneman, \& McCoy, 1992)-children may be more sensitive to differential treatment (Feinberg \& Hetherington, 2001). A similar explanation has emerged from the family systems theory that suggests that parenting operates on both the individual and the family system level. In negative parenting circumstances, the family ethos similarly becomes more negative, which in turn increases insecurity and sensitivity to PDT (Boyle et al., 2004). To the best of our knowledge, no previous study has investigated the combined and interactive effects of ALP and PDT in predicting EPB through the lens of parental support and negative control in a clinical sample with preschoolers referred for EBP.

Theoretical formulations not only stress the association between parent and child factors, but also emphasize the dynamic and changing nature of the parent-child context. For example, Patterson's coercive model (1982), which has been one of the most influential theoretical models on the parent-child dynamic over the past few decades, suggests that coercive exchanges between parents and children have the potential to lead to an escalation of negative behaviors over time. Despite this, research has only recently paid explicit attention to the changing nature of the parent-child context and how these changes may be associated with changes in child adjustment (Richmond, Stocker, \& Rienks, 2005). Decreasing levels of parental support and increasing levels of parental negative control have been shown to worsen EPB in children (Gadeyne, Ghesquière, \&
Onghena, 2004). Similarly, increasing EPB has been demonstrated over time in children who are disfavored compared to their siblings (Richmond et al., 2005). Among the few studies that have investigated the time-varying effect of parenting on child adjustment, several have focused on ALP (e.g., Larsson et al., 2008) whereas others have concentrated on PDT (e.g., Richmond et al., 2005), but none have simultaneously investigated the changing effects of ALP and PDT on child behavior.

The role of fathers in child adjustment is relatively underresearched as most studies on parenting dimensions have focused on mothers (e.g., McHale \& Pawletko, 1992) or on aggregated maternal and paternal parenting into one overall parenting score (e.g., Feinberg et al., 2000; Kowal et al., 2002). Very little existing research has explicitly delineated the processes through which fathers influence their children's behavior (e.g., Cabrera, Shannon, \& Tamis-LeMonda, 2007; Coley \& Medeiros, 2007), while increasing evidence suggests the importance of a differentiated approach from the mother and the father in promoting child adjustment (Lewis \& Lamb, 2003). Although parents often have similar parenting strategies within families, due to both assortative mating and mutual influence and decision-making (Coley, Votruba-Drzal, \& Schindler, 2008), research has shown that mothers tend to engage in more frequent interactions with their children and are more responsive than fathers; fathers tend to be more demanding and have more distant relationships with their children (Lewis \& Lamb, 2003). Previous studies have found that the correlation between parenting and child EPB tends to be higher for mothers than for fathers (see Rothbaum \& Weisz, 1994 for a meta-analytic review), and also that maternal parenting is more strongly predictive of children's EPB than paternal parenting (Aunola \& Nurmi, 2005; Gadeyne et al., 2004; Meunier et al., in press). However, the differentiated and independent ways in which fathers and mothers influence their children's behavior are far from being fully understood.

Parental self-efficacy, child's personality and sibling relationships: Main and moderating effects

Parental self-efficacy (PSE), as described by Bandura (1977), displays strong associations with both positive parenting behavior and child adjustment. Jones and Prinz (2005) suggested that PSE may influence child behavior both directly and indirectly via parenting. Many studies have revealed strong associations between PSE and both dependent (parent report) and independent (not-parent report) measures of child behavior (Jones \& Prinz, 2005). Conceptually, it is difficult to know whether PSE pre-dates and contributes to child behavior problems, and how child behavior contributes to PSE (Jones \& Prinz, 2005). Moreover, most of these studies are limited in inferences of directionality due to their cross-sectional design. The predictive power of self-efficacy has nonetheless been partially demonstrated in studies where interventions aimed at fostering PSE have been found to decrease child behavior problems (e.g., Sofronoff \& Farbotko, 2002). Among studies on PSE, several have explored its relation with parenting, whereas others have investigated its direct associations with child outcomes. However, to our knowledge, PSE and parental behavior have not previously been examined simultaneously with respect to children's psychological adjustment. To this extent, the direct effect of PSE on child adjustment has never been demonstrated after controlling for the effect of parenting behavior. In this study, we are interested in the unique effects of PSE on child EPB above and beyond the effects of ALP and PDT. As suggested by Jones and Prinz (2005), an additional direct contribution of PSE is consistent with social learning theory (Patterson, 1982) because children may learn behavioral strategies by listening to and watching the ways in which their parents undertake their childrearing role.

Studies of personal etiological factors explaining EPB have often included temperament/personality as an antecedent to behavioral 
development, with negative emotionality as a general risk factor (Eisenberg, Fabes, Guthrie, \& Reiser, 2000). However, evidence suggests that temperament/personality does not, by itself, lead to problem behavior; this only occurs in conjunction with particular environmental features, such as parenting. Initially, the goodness-offit theory (Thomas \& Chess, 1977) suggests that problem behavior emerges when there was a mismatch between the child's temperament and the parents' behavior. A growing body of studies corroborates this interaction between child personal characteristicsfor both temperament and personality-and parenting (Kochanska, Aksan, \& Joy, 2007), and also shows that children with difficult traits are particularly vulnerable when exposed to unskilled parenting (e.g., Van Leeuwen et al., 2004). More specifically on personality, Prinzie et al. (2003) demonstrated through a cross-sectional design that child agreeableness functioned as a protective factor, buffering the effect of maternal or paternal over-reactivity on children's EPB. They also demonstrated that coercive paternal behavior was more strongly related to EPB for children low on conscientiousness. Using a longitudinal design, Van Leeuwen et al. (2004) replicated this pattern of interactions, but also found that parental support tended to buffer the effect of low agreeableness in predicting EPB. However, they used combined scores for the two parents, thereby hiding the individual contribution of mothers and fathers. Although an interaction between PDT and personality has not been previously demonstrated, some recent findings suggest that such an interaction may exist. Meunier and Roskam (2009a) demonstrated that children's perception of favoritism was partly explained by personality traits-emotional stability and agreeableness-which in turn suggested that children may be differentially affected by unequal treatment according to their personality.

A body of literature has also related EPB with the quality of relationships between siblings. It has been hypothesized that a low quality sibling relationship, characterized by frequent conflictual and coercive interactions and low positivity, may set the stage for training children in antisocial behavior (Bank, Patterson, \& Reid, 1996). Other longitudinal research has shown that the quality of sibling relationships in early childhood predicted adjustment later in adolescence (Hetherington, Henderson, \& Reiss, 1999). The present study examines the effects of sibling relationships on EPB simultaneously with the parenting dimensions. As suggested in previous studies, this is particularly important because several parental dimensions-especially PDT-have been related to poorer sibling relationships (e.g., Brody et al., 1992). This should allow a better understanding of the contributions of different components of family context to predicting children's adjustment difficulties. Furthermore, it has recently been demonstrated that the sibling relationship may moderate the association between PDT and EPB (Scholte, Engels, de Kemp, Harakeh, \& Overbeek, 2007), with positive relationships being a protective factor. In other words, feeling disfavored compared to a sibling seems to have a more negative effect on EPB when the sibling relationship is negative, than when the sibling relationship is affectionate. However, results for sibling relationships and their combined effect with PDT on EPB have not been consistently demonstrated in studies using the MLM framework (see, for example, Kim, MacHale, Crouter, \& Osgood, 2007; Richmond et al., 2005) and are therefore explored further in this study.

\section{Multi-informant approach on EPB: Parents' rating vs. observation}

The present study used a multi-informant strategy with regard to child behavior. This has the advantage of both avoiding sharedmethod variance between predictor and outcome measures, and of partly coping with measurement biases in the assessment of behavioral problems. Child behavior was assessed by both parents (using a questionnaire), as well as through observations. Although informative, each procedure has its drawbacks and may suffer from bias. Parents are usually the most privileged informants on pre- schoolers' behavior, insofar as preschoolers spend a lot of time in the family setting. However, parents' ratings of EPB are known to be negatively biased because they are more emotionally involved with their children's disruptive behavior than are teachers or external observers (Roskam, Meunier, Stievenaert, \& Van de Moortele, 2009; Van der Ende \& Verhulst, 2005). Direct observations provide a valuable complementary means of behavioral assessment by avoiding both informant effects and the influence of past transactions on how current behavior is interpreted (Hughes et al., 2002). Nevertheless, observations have been shown to be strongly influenced by day-today variability in behavior (Epstein, 1983; Hops, Davis, \& Longoria, 1995). In this context, the standardized format of the observational paradigm used in the present study has demonstrated to minimize such variability and to provide strong ecological validity (Hughes et al., 2002). By relating predictors to child behavior, both as rated by parents and as observed by external raters, the present study aims to depict a more complete and objective view of within-family processes.

\section{Current study}

In sum, we intend to investigate the effects of both level-of and change-in ALP and PDT on change in EPB. It is hypothesized that low parental support and high parental negative control, as well as disfavored treatment and deterioration over time in these dimensions, will predict higher EPB in children at a later date. In addition to parenting, the effects of child personality, sibling relationships and PSE are explored and hypothesized to explain additional and independent amounts of variance in future EPB. Associations are expected between adjusted personality traits-especially emotional stability-positive sibling relationships, high PSE and lower EPB. In addition to simple additive effects, several moderating effects are expected between the predictors: (a) an ALP $\times$ PDT interaction where disfavoring PDT is expected to be more deleterious for EPB when ALP is more negative; (b) an ALP and/or PDT $\times$ personality interaction with child agreeableness, conscientiousness and emotional stability as potential protective factors; and (c) a PDT $\times$ sibling relationships interaction with disfavoring differential treatment being more deleterious for children with negative sibling relationships. Finally, models are tested for the two parents separately and using both parental reports and observational assessments of EPB.

\section{Method}

\section{Samples and procedure}

This study was part of the "H2M-children" research program which is an investigation geared at identifying the early predictors of EPB in children. The data collection is carried out by the Department of Psychology at the Université catholique de Louvain in Belgium in collaboration with St Luc University Clinic in Brussels (see http:// www.uclouvain.be/h2m-children.html for more details). Data were collected from a sample of 119 families-drawn from the Frenchspeaking area of Belgium-that had a preschooler who had been referred for EPB (arousal, opposition, agitation, aggressiveness, or non-compliance). The referral had to have been made by a physician after a diagnosis of EPB, which was the immediate and principal reason for the referral. The parents were informed about the study and were assured that the data would remain confidential. Informed consent was obtained from all the adult participants. The cohort was recruited when the children were between 3 and 5 years old. Data came from three waves of assessment that occurred on a yearly basis. At the time they were recruited (T1), all the children were attending normal preschool. Overall, 47 were in the first preschool year, 39 were in the second and 31 were in the third. The mean age of the children at T1 was 3.90 years $(S D=.87)$. Boys were over represented in the 
sample, at 93 (3.84 years, $S D=.84$ ) compared to 26 girls (4.12 years, $S D=.97)$. All parents had the Belgian nationality and a vast majority of them were of Caucasian origin (96.6\% of the mothers and $93.3 \%$ of the fathers). Their educational level was taken as the number of years of education they had completed, counting from first grade onward. Some $25.7 \%$ of mothers had completed 12 or fewer years (corresponding to the end of secondary school in Belgium); 56.0\% had completed three more years (corresponding to undergraduate study); whereas $18.3 \%$ had achieved a 4 -year degree or more. Amongst fathers, $36.9 \%$ had completed 12 or fewer years of education, $42.7 \%$ had achieved an undergraduate degree, and $20.4 \%$ had four or more years of university. The majority of parents in the sample were working (either full-time or part-time), with $20.2 \%$ of the mothers and $8.4 \%$ of the fathers being unemployed at the time of the onset of the study. Most of the parents lived in two-parent families (88.3\%), but $11.7 \%$ were separated or divorced. Of the families who took part in the study, $21.8 \%$ had one child, $39.5 \%$ had two children, $25.2 \%$ had three children and $13.6 \%$ had four or more children. In sum, 93 children came from families with two or more children.

Three research assistants (all professional clinicians) were involved in collecting data. At each wave of assessment, the parents were seen by one of the research assistants at the Department of Psychology and a short semi-structured interview was conducted (for anamnestic purposes at $\mathrm{T} 1$ or follow-up investigation at T2 and T3). At T1, both parents were also asked to complete questionnaires assessing their parental behavior and self-efficacy, as well as their child's personality and behavior. If the target child had sibling(s), the parents were asked to complete two additional questionnaires about their parental behavior towards the closest-in-age (older or younger) sibling, as well as the sibling relationships between the target child and the target sibling. At T2 and T3, the parents were again asked to fill out the questionnaires related to their child's behavior and their parental behavior toward the target child (and his or her closest-in-age sibling, if applicable). During each assessment period (two to four weeks after the completion of the questionnaires), the child was also visited at school by a research assistant to collect observational data by means of the SNAP-game. At the second school visit (T2), the children who were then at least 4 years old were asked to complete a set of questions related to their relationships with their closest-in-age sibling. The questions were read by the research assistant to the children, who responded verbally. Of the 119 families involved at T1, 17 families declined to participate at T2, and 4 others at T3. Amongst the 93 families eligible for a sibling assessment, only sibling dyads with less than 4 years between them (86 sibling dyads) were considered, in order to partially control for age spacing (Tamrouti-Makkink et al., 2004).

\section{Measures}

\section{Child behavior}

Child behavior was assessed by both parents through questionnaires, as well as through observational coding methods. Parents completed the Anger-Aggression subscale on the French version of the Social Competence and Behavior Evaluation-30 (SCBE-30; LaFrenière \& Dumas, 1996). This scale has a developmental background that emphasizes the functional meaning of affect in regulating social interactions (Ekman, 1984). Items are in the form of adjectives, for example: "Irritable" or "Angry when interrupted". The original validation study found that the 10 items composing the AngerAggression subscale displayed high internal consistency on four independent samples (Cronbach's $\alpha$ of .92 in each sample). Moreover, the SCBE-30 has been widely validated across different cultures and different samples (e.g., LaFrenière et al., 2002).

Preschoolers' disruptive behavior was assessed by the research assistants. An observational paradigm called the SNAP-game was used. It consists of a rigged competitive card game between two children designed to expose them to the threat of losing. This paradigm has been shown to be useful and valid for assessing disruptive behavior in young children (Hughes et al., 2002). During the school visit, the children in our sample were asked to identify one of their classmates as a partner for the game. The play session was videotaped and took place in a quiet room at school with the research assistant. Both children experienced frustration during half of the card games (loosing deals) and behavioral reactions were observed during these frustrating deals. Social interactions, positive affect, negative affect, arousal and aggression were coded at each loosing deal using a 5-point Likert-type scale and by taking into account the intensity and frequency of adaptive and disruptive behavior. For example, the criteria for rating aggression on the 5-point scale were as follows: 1, No aggression; 2, Verbal assertion or masked aggression (says "it's not fair" with irritation, hits his/her head,..); 3, Explicit verbal aggression or sustained masked aggression (says "you're cheating" with irritation, pretends to hit the peer,...); 4, Excessive verbal aggression or episode of mild physical aggression; 5, Extreme irritation or episode of explicit physical aggression. Each of the deals was coded separately by two independent coders. The agreement between the two coders was high, $r=.94$ to .97 . For the disruptive behavior measure to be computed, only scores on negative affect, arousal and aggression were considered and averaged.

Pearson correlation coefficients were used to compare the two EPB measures. The results indicate only weak association (.06, ns at T1; $.14, p<.05$ at T2; .08, ns at T3, and $.12, p<.10$ on average across all three waves). Although close to or below the $5 \%$ level of significance, this finding is in accord with previous results (Hughes et al., 2002) and suggests that the two EPB measures would preferably be used as separate outcomes.

\section{Parental behavior}

Parental behavior was assessed by the Evaluation des Pratiques Educatives Parentales (EPEP, Meunier \& Roskam, 2007). This is based on previous studies by Van Leeuwen and Vermulst (2004) and Patterson (1982), and contains 35 items relating to nine factors: Positive Parenting, Monitoring, Rules, Discipline, Inconsistent Discipline, Harsh Punishment, Ignoring, Material Rewarding, and Autonomy. Items are in the form of affirmatives, for example: "I give my child a compliment, hug or a tap on the shoulder as a reward for good behavior" for Positive Parenting, or "When my child gets on my nerves or is really exasperating, I occasionally resort to physical punishment (spanking, slapping)", for Harsh Punishment. Recently validated on 493 French-speaking mothers and fathers of normally-developing children, the EPEP scale has good psychometric properties. Cronbach's $\alpha$ ranged from .65 to .89; the total percentage of variance explained by the nine factors was $64.3 \%$; test-retest correlations for a sample of 45 parents varied between .51 and .84; and the items were not correlated with social desirability. Confirmatory factor analyses (CFA) showed that two second-order factors covering the Support and Negative Control parenting dimensions reported in the literature (Aunola \& Nurmi, 2005; Baumrind, 1971) emerged from the initial factor solution. The Supportive factor was composed of Positive Parenting, Autonomy, Monitoring, and Rules, whereas the Negative Controlling factor included Discipline, Harsh Punishment, Material Rewarding, Inconsistent Discipline and Ignoring. Aggregated scores for the Supportive and the Negative Controlling factors were obtained by averaging the scores of the underlying subscales. The correlation between the two second-order factors were low and non significant for the two parents ( $r$ from -.05 to $-.09, n s$, for the mothers and $r$ from -.06 to -.12 , ns, for the fathers). Measures of ALP and PDT were derivated from the EPEP and their construction will be detailed in the next section.

\section{Parental self-efficacy (PSE)}

Parental self-efficacy was assessed by the Echelle Globale du Sentiment de Compétence Parentale (EGSCP, Meunier \& Roskam, 2009b). Based on Bandura's self-efficacy theory (1977), the EGSCP is a 
25-item scale related to five domain-specific self-efficacy factors: Discipline, Nurturance, Playing, Instrumental Care, and Teaching. Items are in the form of affirmatives, for example: "I am able to sense when my child is starting to become distressed" in the case of Nurturance. It was validated on 705 French-speaking parents of nonreferred children. Cronbach's $\alpha$ varied from .60 to .84 , and the total amount of variance explained by the factors was $53.07 \%$. Positive correlations were reported with marital support, parental well-being, and the support parenting dimension. Negative correlations were reported with children's behavioral problems and the negative control parenting dimension.

\section{Child personality}

Child personality was assessed by completing the Bipolar Rating Scales based on the Big Five model (EBMCF, Roskam, de MaereGaudissart, \& Vandenplas-Holper, 2000). This scale has 25 items, 5 for each of the five factors: Extraversion, Agreeableness, Conscientiousness, Emotional Stability and Openness. Items are in the form of pairs of adjectives, for example "Reserved-Spontaneous" for Extraversion. A 9-point Likert-type scale is provided under each item, with the bestadjusted personality trait at the top of the scale. It has been validated on a sample of 1,196 mothers of non-referred children. Cronbach's $\alpha$ varied from .67 to .90 , test-retest correlations varied between .80 and .89 , and the total amount of variance explained by the factors was $60.5 \%$. The scales were not correlated with social desirability.

\section{Sibling relationships}

Sibling relationships were assessed by both the parents and the target child. Parents completed the Companionship/Involvement (6 items) and the Conflict (5 items) subscale of the revised version of the Sibling Inventory of Behavior (SIB, Hetherington et al., 1999). Items are in the form of affirmatives, for example: "Treats (sibling) as a good friend", for Companionships/Involvement, and "Has physical fights with (sibling) (not just for fun)", for Conflict. Initially developed by Schaefer and Edgerton (1981), the SIB has been used quite extensively by researchers and has been shown to be psychometrically sound. It has adequate internal consistency and cross-time correlations, as well as impressive associations across respondents (Volling \& Blandon, 2005). Based on the validation of its revised form (Hetherington et al., 1999), the Cronbach's $\alpha$ of the SIB scales used in this study demonstrated good internal consistency (.70 and above).

As children's reports of their sibling relationships have been demonstrated to be reliable only at the age of 4 or above (Measelle, Ablow, Cowan, \& Cowan, 1998), the children were only asked to assess their sibling relationships at T2 (school visit) by completing the Hostility and Affection scales of the Sibling Relationships Inventory (SRI, Boer, Westenberg, McHale, Updegraff, \& Stocker, 1997). The SRI has been demonstrated to give a meaningful evaluation of sibling relationships for children as young as 4 (Boer et al., 1997). There were 8 items on the Affection scale, for example "How much do you admire (sibling), I mean, do you think she/he is pretty special or neat?" and 5 on the Hostility scale, for example "How often do you feel mad or angry at (sibling)?" The initial validation on 206 American and 452 Dutch siblings demonstrated good psychometric properties (Boer et al., 1997) with a high percentage of variance explained by the two factors and Cronbach's $\alpha$ of .78 for Affection and .70 for Hostility.

\section{Treatment}

To measure participation in treatment, parents were also asked at the last assessment wave how often, from wave 1 onward, they and/or their child had gone to a professional (e.g., psychologist, therapist, mental health center or parental counselor) for their child's behavioral problems. Based on this information, a Likert scale was constructed ranging from 0 to 4 and defined as followed: 0 , no treatment at all; 1 , sporadically (less than 5 times during the whole study period); 2 , regularly (twice a month or more) during a period of 6 months or less; 3 , regularly (twice a month or more) during a period from 6 months to 12 months; 4, regularly (twice a month or more) during a period of more than 12 months. An additional point was given if they had undergone more than one type of treatment simultaneously for a period of at least 3 months (e.g., child's therapist and parental counselor).

\section{Measurement considerations}

Considering the complexity of the analyses, including numerous predictors-both time-varying and -invariant-and a multi-informant approach, a number of composite scores were created to reduce the potential number of analyses. ALP and PDT were considered as both time-varying and -invariant predictors and their measures were derived from the EPEP (Meunier \& Roskam, 2007). For the ALP, a support-to-negative-control ratio was calculated with a score of 1 indicating equal amounts of support and negative control, a score less than 1 indicating more negative control than support, and a score greater than 1 indicating more support than negative control. For the PDT, within-family differences in parenting were measured using the simple difference model (Feinberg \& Hetherington, 2001) by subtracting the sibling's score from the target child's score on the ALP measure. Thus, a negative score indicates "self disfavored", a score of 0 indicates "equal treatment", and a positive score indicates "self favored". Although parenting is more commonly considered in existing research by using separated dimensions-such as support and negative control (Aunola \& Nurmi, 2005)-the use of a general parenting construct was preferred for several reasons beside data reduction purpose. First, in view of Rothbaum and Weisz's (1994) meta-analytic review, composite measures of parenting are recognized to provide more predictive power than do more specific dimensions. In this respect, studies using specifically a composite support-negative control measure-as we did-found increased prediction on EPB as compared to disaggregated scores (Belsky, Hsieh, \& Crnic, 1998; McFadyen-Kethum, Bates, Dodge, \& Pettit, 1996). Second, although time-varying covariates represented a unique way to model the effect of change in a predictor on change in an outcome, it cannot rule out the possibility of reciprocal causation, as assessment periods are contemporaneous for all repeated measure-predictors and outcomes (Singer \& Willett, 2003). As the inclusion of numerous timevarying predictors may raise serious interpretative dilemmas (Singer \& Willett, 2003), we limited our use of time-varying predictors to single measures for ALP and for PDT. Finally, the single measure approach was thought to be best suited for examining the respective contribution of ALP and PDT in predicting child's EPB trajectories.

Parental self-efficacy (PSE), sibling relationships and child personality were introduced in our analyses as time-invariant predictors. ${ }^{1}$ For PSE, a composite score was obtained by averaging the scores for the five EGSCP factors as they were shown to be internally consistent (Cronbach's $\alpha$ of .70 for mothers and .80 for fathers). This procedure is furthermore in line with Bandura's formulation (1977) which suggested that the most valid approach for determining the domain-level self-efficacy of a multidimensional construct-such as parenting-is achieved by combining the efficacy information conveyed by several behaviorally specific assessments. For the sibling relationships, a composite score was constructed by capitalizing on the double perspective of the parents and the children. Although this procedure violates the temporal precedence necessary for prediction (children's ratings at T2), the cross-rater strategy was chosen in order

\footnotetext{
${ }^{1}$ Contrary to personality which is recognized to be quite stable over time (Prinzie et al., 2003), PSE and sibling relationships may change over time-a.o. as a function of family contingencies-(Jones \& Prinz, 2005; Richmond et al., 2005) and could have been introduced as time-varying covariates into the present analyses. However, as reciprocal causation is recognized between these constructs and both parent and child behavior (Jones \& Prinz, 2005; Richmond et al., 2005), they were introduced as timeinvariant predictors for the interpretative concerns mentioned before.
} 
to lessen shared-method variance (for example with the SCBE-30). Parent-child agreement on sibling relationships was quite modest (correlations around .20) but nonetheless significant at $p<.05$. This was consistent with previous studies suggesting that parents' and children's perspectives do not mimic each other and should therefore be seen as complementary (Jenkins, Dunn, O'Connor, Rasbash, \& Behnke, 2005). For these reasons, mean scores for parents and children were computed for the Companionship/Involvement and Affection scales and for the Conflict and Hostility scales. The correlation between the averaged affection score and the averaged conflict score was moderate and negative, $r=-.33, p<.01$. As for the ALP measure, a unique affection-to-conflict ratio was calculated (Richmond et al., 2005) with a score of 1 indicating equal amounts of affection and conflict, a score less than 1 indicating more conflict than affection, and a score greater than 1 indicating more affection than conflict. Contrary to the other predictors, which were based on composite scores, personality was considered by using the five personality factors separately as hypotheses were made about specific personality traits (e.g., Van Leeuwen et al., 2004). Although hypotheses were not made about each of the personality traits, they were all taken into account in the present study considering the limited existing results and the specificity of our methodology compared to previous studies.

\section{Analysis strategy}

To examine the developmental course of EPB in young children, the main analyses in the present study were conducted using a multilevel modeling (MLM) framework with the HLM 6.06 software (Raudenbush, Bryk, Cheong, \& Congdon, 2008). The MLM framework capitalizes on the multilevel structure of the data, providing information about the variability of individuals over timeLevel 1 (repeated measures)-as well as between individuals-Level 2 (Raudenbush \& Bryk, 2002). MLM provides a flexible method of modeling change over time with several advantages over other methods. First, attrition is common in longitudinal data and MLM estimates are based on all the available data, with the assumption that the data are missing at random (MAR) (Raudenbush \& Bryk, 2002). To test the plausibility of this assumption, ${ }^{2}$ we followed the recommendations proposed by McCartney, Burchinal and Bub (2006). The statistical analyses showed that the pattern of missing data was not associated with background measures, such as parent educational level, sibling number, child age and gender, nor with the variables under investigation as assessed at the first wave. Thus, the missing data presented little threat to the validity of the study, and were considered as MAR. Second, MLM allows both time-varying and timeinvariant predictors to be included in the models (Raudenbush, Brennan, \& Barnett, 1995). As a result, we were able to predict the changes in EPB from the changes in parenting (ALP and PDT) as well as from time-invariant predictors such as PSE and the child's personality. All the analyses were conduced separately for the mothers and the fathers, as well as for the two EPB outcome measures (SCBE-30 and SNAP-game). As is customary, two set of unconditional models-one with no predictor (unconditional means models) and one in which time is the only predictor (unconditional growth models)-were tested for the two EPB outcome measures before testing models with predictors of level and change (conditional models).

\section{Unconditional models}

The unconditional means models were only run to calculate the Intraclass Correlation Coefficient (ICC) and are therefore not presented in table. The ICC-estimated by dividing the Level 2 variance by the total

\footnotetext{
2 "When data are missing beyond the invesigator's control, one can never be certain whether MAR holds. The MAR hypothesis in such data sets cannot be formally tested unless the missing values, or at least a sample of them, are available from an external source (Schafer, 1997, p. 22)."
}

variance in a model with no predictors-allowed us to evaluate the relative magnitude of the within-person (Level 1) and the betweenperson (Level 2) variance components the two EPB measures. The ICC also is a measure of the average autocorrelation of the dependent variable over time (Singer \& Willett, 2003) giving an index of the average stability of the two EPB measures. The unconditional growth models were tested to examine the developmental trajectories of EPB as assessed by the two measures (Table 3 ). The time component used was the wave number minus 1 (i.e. $0,1,2$ ) that set the first wave as the reference category and permitted us to interpret the intercept as the baseline level of EPB at the outset of the study. The slope indicated by the regression coefficient of the time component represents the developmental trajectories of the child EPB. The unconditional growth models can also determine whether there is significant variability between individuals in the intercept and the slope coefficients. If significant variability is detected then it is justifiable to include other variables in the model to predict difference in individuals' intercepts and/or slopes.

\section{Conditional models}

The first set of models was tested in three steps. They examined whether level-of and change-in ALP and PDT predicted the developmental course of EPB, and whether there was any ALP $\times$ PDT interaction in such predictions. The predictive effect of ALP and PDT for EPB were first examined separately (Steps 1 and 2) and then entered simultaneously, along with the interaction term between the average levels of ALP and PDT (Step 3). Time-varying predictors were added in the Level 1 equation, and time invariant predictors were added in the Level 2 equation (see Raudenbush et al., 1995). At Level 1 , the time-varying predictors were group-mean (or within-person) centered in order to address bias due to unobserved heterogeneity, or unmeasured factors that vary across individuals and have a consistent effect over time on the construct of interest (Raudenbush \& Bryk, 2002). The time-varying predictors were also constrained to have fixed effects (Raudenbush et al., 1995). If significant variability existed around the intercept and/or the slope, the average level of ALP and PDT over the three time periods was calculated, and added as predictors of the intercept and/or slope coefficient at Level 2. In Step 3, any ALP $\times$ PDT interactions were also entered at Level 2 on a similar basis. As suggested by Aiken and West (1991), interaction terms were calculated by multiplying grand-mean-centered main-effect terms in order to eliminate multicollinearity.

The two other sets of models tested the additive or combined effects of the remaining predictors (PSE, child personality etc.) with the parental behavior measures, but separately for ALP and PDT in order to maximize sample size and to limit the number of predictors. The second set of models maintained the time-varying effects of ALP in predicting EPB at Level 1, and its invariant effects at Level 2. In addition, the PSE and child personality factors were grand-mean centered and entered at Level 2 as predictors of the intercept and/or the slope. Because the specific hypotheses about personality traits implied numerous predictors ( 5 main effects and 5 interaction terms), each personality trait along with its interaction term with ALP was tested in a separate model. The third set of models used the timevarying and invariant effects of PDT to predict EPB, at Levels 1 and 2 respectively. PSE and child personality were included in this model along with sibling relationships. As with ALP, and for the same reason, each child personality trait and the sibling relationship were tested separately along with their interaction with PDT.

\section{Results}

\section{Preliminary analyses}

The mean, standard deviation, and range for all variables are presented in Table 1. All the variables were normally distributed and the repeated measures displayed homogeneity of variance over time. 
Table 1

Descriptive statistics.

\begin{tabular}{|c|c|c|c|}
\hline Variables and label & Mean & $S D$ & Range \\
\hline \multicolumn{4}{|c|}{ Externalizing problem behavior (EPB) } \\
\hline $\mathrm{SCBE} 30$ at $\mathrm{T} 1$ & 52.37 & 14.18 & 18.00 to 88.00 \\
\hline SCBE-30 at $\mathrm{T} 2$ & 48.50 & 13.96 & 22.00 to 88.00 \\
\hline SCBE-30 at T3 & 47.58 & 15.81 & 14.00 to 88.00 \\
\hline Mean SCBE-30 & 50.74 & 13.11 & 24.75 to 88.00 \\
\hline SNAP-game T1 & 2.18 & .31 & 1.48 to 3.00 \\
\hline SNAP-game T2 & 2.14 & .33 & 1.44 to 3.07 \\
\hline SNAP-game T3 & 2.17 & .33 & 1.15 to 3.33 \\
\hline Mean SNAP-game & 2.17 & .26 & 1.63 to 3.00 \\
\hline \multicolumn{4}{|c|}{ Absolute level of parenting (ALP) } \\
\hline Mothers at T1 & 1.56 & .41 & .72 to 2.89 \\
\hline Mothers at T2 & 1.66 & .44 & .70 to 3.04 \\
\hline Mothers at T3 & 1.66 & .41 & .72 to 2.89 \\
\hline Mean mothers & 1.63 & .39 & .71 to 2.89 \\
\hline Fathers T1 & 1.57 & .45 & .75 to 3.54 \\
\hline Fathers T2 & 1.60 & .44 & .71 to 3.54 \\
\hline Fathers T3 & 1.66 & .45 & .72 to 3.67 \\
\hline Mean fathers & 1.61 & .41 & .75 to 3.29 \\
\hline \multicolumn{4}{|c|}{ Parental differential treatment (PDT) } \\
\hline Mothers at T1 & -.21 & .50 & -2.46 to 0.45 \\
\hline Mothers at T2 & -.22 & .42 & -2.77 to 0.38 \\
\hline Mothers at T3 & -.23 & .44 & -2.43 to 0.38 \\
\hline Mean mothers & -.22 & .41 & -2.61 to 0.38 \\
\hline Fathers at $\mathrm{T} 1$ & -.26 & .50 & -1.62 to 0.84 \\
\hline Fathers at $\mathrm{T} 2$ & -.19 & .49 & -1.85 to 1.46 \\
\hline Fathers at T3 & -.22 & .51 & -2.01 to 1.02 \\
\hline Mean fathers & -.23 & .45 & -1.62 to 1.11 \\
\hline \multicolumn{4}{|l|}{ Parental self-efficacy (PSE) } \\
\hline Mothers & 3.71 & .39 & 2.70 to 4.61 \\
\hline Fathers & 3.71 & .42 & 2.31 to 4.71 \\
\hline \multicolumn{4}{|l|}{ Sibling relationships (SR) } \\
\hline & 1.45 & .62 & .41 to 3.88 \\
\hline \multicolumn{4}{|l|}{ Child's personality } \\
\hline Extraversion (EXT) & 6.70 & .99 & 3.67 to 8.70 \\
\hline Agreeableness (AGR) & 6.44 & 1.07 & 3.70 to 9.00 \\
\hline Conscientiousness (CON) & 4.82 & 1.41 & 1.80 to 7.95 \\
\hline Emotional stability (EMS) & 3.79 & 1.06 & 1.00 to 5.90 \\
\hline Openness (OP) & 7.43 & .95 & 4.70 to 9.00 \\
\hline \multicolumn{4}{|l|}{ Treatment } \\
\hline & 1.69 & 1.24 & 0 to 4 \\
\hline
\end{tabular}

The EPB scores as assessed by parents (SCBE-30) decreased over time, but scores on the observational measure (SNAP-game) remained quite stable. The means for the parenting (ALP) and sibling relationship variables are directly interpretable and indicate that, on average, the referred children received more support than control from both their parents, and displayed more affection than hostility towards their nearest-in-age sibling (all values above 1). However, they were somewhat disfavored by parents compared to this sibling (negative PDT values). The top part of Table 2 presents the correlation coefficients between the constructs under investigation. In order to ease the readability of the results, only the first wave scores of the repeated measures were considered in the correlation matrix. The two EPB measures showed expected correlations with the other variables but with weaker associations for the observational measure. The SCBE-30 was associated with all other constructs except father PDT, but the SNAP-game was only associated with mother ALP and PSE and with child personality (conscientiousness). Associations were moderate to large between mother and father parental variables (ALP, PDT and PSE). No associations were found between the same parents' measures of ALP and PDT. Quite surprisingly, however, negative associations were found across mother and father measures of ALP and PDT suggesting that the more positive treatment the target child receives from one parent, the more he/she is disfavored by the other parents. The bottom part of Table 2 displays the stability over time of the repeated measures. The results show high stability in EPB as assessed by parents (SCBE-30), as well as in the parenting measures. Surprisingly, however, in the observational setting, EPB was only moderately correlated between consecutive waves (T1 and T2, and T2 and T3), and the correlation between the initial and final waves (T1 and T3) was not significant.

\section{Unconditional models}

Estimated from the unconditional means models, the ICCs were .69 for the SCBE-30 and .14 for the SNAP-game. This suggests that the variance of the SCBE-30 was more largely due to difference between children (69\%) whereas the variance of the SNAP-game was more largely due to variation within children (86\%). The ICCs also indicated, as we previously found (see Table 2, bottom part), that EPB were much more stable as assessed by the SCBE-30 (average stability .69) than by the SNAP-game (average stability .14). From the unconditional growth models estimating the developmental trajectories of EPB (Table 3), the fixed effects of the SCBE-30 model indicate that both the intercept and the slope were significantly different from zero. The intercept indicates that the average SCBE-30 score at the outset of the study was 52.46 . The negative slope indicates a significant linear decline in EPB over time. With the SNAP-game as outcome, the fixed effects of the model show that only the intercept was significant, indicating an average score of 2.17 at the onset of the study. The non significant slope suggests that children did not show any linear change in their EPB over time, as assessed by the SNAP-game. More important, and central to the goals of this study, were results from the random part of the models. For the SCBE-30 model, the results indicate that there was significant individual variability around both the intercept and the slope. For the SNAP-game, significant individual variability was only observed around the slope (but not around the intercept). Predictors at Level 2 were therefore examined for both the intercept and the slope in the SCBE-30 model and only for the slope in the SNAP-game model. Before considering the predictors under investigation in the present study (see next section), the treatment effect was tested and showed no effect on the developmental trajectories of EPB, both as assessed by the SCBE-30 $(\gamma=.12, n s)$ and by the SNAP-game $(\gamma=.005, n s)$. For this reason, the treatment variable was not included in the subsequent models.

\section{Conditional models}

The first set of models examined the main effects of ALP and PDT on changes in child EPB, as well as their interaction effects. As the conditional models include time-varying covariates, the randomeffect coefficients around the intercept and the slope are no longer comparable to the unconditional models ${ }^{3}$ and are therefore not presented.

For the mother (Table 4), results for the Level 1 predictors (timevarying) indicated that changes in ALP (but not changes in PDT) were associated with changes in EPB $(\gamma=-4.40, p<.10)$, as assessed by the SCBE-30. This marginally significant result indicates that $1 S D$ of positive change in mothers' ALP in a 1-year interval was associated with a decrease of .13 of a SD in EPB. However, once changes in both ALP and PDT were included in the model, the ALP effect was no longer significant. For the SNAP-game, results show that only changes in PDT (but not changes in ALP) were associated with changes in EPB (with $\gamma=-.18, p<.05$ ), indicating that $1 S D$ of positive change in mothers' PDT in a 1-year interval was associated with a decrease of .28 of a SD in

\footnotetext{
${ }^{3}$ Unlike Level 2 predictors which essentially affect the Level 2 variance components, time-varying predictors (Level 1) can affect all variance components because they vary both within- and between-person. For this reason, change in Level 2 variance components is no longer meaningful (Singer \& Willett, 2003).
} 
Table 2

Pearson correlation coefficients examining the associations between the constructs and the stability of the repeated measures over time.

\begin{tabular}{|c|c|c|c|c|c|c|c|c|c|c|c|c|c|c|}
\hline \multicolumn{15}{|l|}{ Associations between the constructs } \\
\hline & 1. & 2. & 3. & 4. & 5. & 6. & 7. & 8. & 9. & 10. & 11. & 12. & 13. & 14 . \\
\hline 1. Children's EPB (SCBE-30) T1 & - & & & & & & & & & & & & & \\
\hline 2. Children's EPB (SNAP-game) T1 & .06 & - & & & & & & & & & & & & \\
\hline 3. Mothers' ALP T1 & $-.16^{*}$ & $-.20^{*}$ & - & & & & & & & & & & & \\
\hline 4. Fathers' ALP T1 & $-.29 * *$ & -.08 & $.42^{* * *}$ & - & & & & & & & & & & \\
\hline 5. Mothers' PDT T1 & $-.16 \dagger$ & -.07 & .01 & $-.40^{* * *}$ & - & & & & & & & & & \\
\hline 6. Fathers' PDT T1 & .06 & -.02 & $-.27^{* *}$ & .06 & $.56^{* * *}$ & - & & & & & & & & \\
\hline 7. Mothers' PSE & $-.25^{* *}$ & $-.18^{*}$ & $.40^{* * *}$ & .12 & .01 & -.14 & - & & & & & & & \\
\hline 8. Fathers' PSE & $-.16 \dagger$ & .01 & $.22^{* *}$ & $.24^{* *}$ & .06 & .06 & $.23^{* *}$ & - & & & & & & \\
\hline 9. Extraversion & -.06 & .07 & $.14 \dagger$ & $.22 *$ & $-.15 \dagger$ & $-.17 \dagger$ & -.07 & .11 & - & & & & & \\
\hline 10. Agreeableness & $-.50^{* * *}$ & .02 & .09 & $.24^{* *}$ & $-.29^{* *}$ & $-.16 \dagger$ & .12 & $.14 \dagger$ & $.39^{* * *}$ & - & & & & \\
\hline 11. Conscientiousness & -.06 & $-.17^{*}$ & .09 & $.13 \dagger$ & -.02 & .05 & .07 & $.14 \dagger$ & .10 & $.20^{*}$ & - & & & \\
\hline 12. Emotional stability & $-.41^{* * *}$ & -.06 & .08 & $.15 \dagger$ & .03 & -.01 & $.13 \dagger$ & .11 & $.15 \dagger$ & $.30^{* *}$ & $.39 * * *$ & - & & \\
\hline 13. Openness & -.10 & -.02 & $.17^{*}$ & $.29^{* *}$ & $-.19^{*}$ & -.08 & .02 & .03 & $.44^{* * *}$ & $.39^{* * *}$ & $.37^{* * *}$ & .10 & - & \\
\hline 14. Sibling relationships & $-.37^{* *}$ & -.02 & $.17 \dagger$ & $.40^{* * *}$ & $-.35^{* *}$ & -.09 & $.18 \dagger$ & $.17 \dagger$ & $.15 \dagger$ & $.31^{* *}$ & -.06 & .01 & .12 & - \\
\hline
\end{tabular}

\begin{tabular}{|c|c|c|c|c|c|c|c|c|c|c|c|c|}
\hline & \multicolumn{2}{|c|}{$\begin{array}{c}\text { Children's EPB } \\
\text { (SCBE-30) }\end{array}$} & \multicolumn{2}{|c|}{$\begin{array}{l}\text { Children's EPB } \\
\text { (SNAP-game) }\end{array}$} & \multicolumn{2}{|c|}{ Mothers' ALP } & \multicolumn{2}{|c|}{ Mothers' PDT } & \multicolumn{2}{|c|}{ Fathers' ALP } & \multicolumn{2}{|c|}{ Fathers' PDT } \\
\hline & $\mathrm{T} 2$ & T3 & $\mathrm{T} 2$ & T3 & $\mathrm{T} 2$ & T3 & $\mathrm{T} 2$ & T3 & $\mathrm{T} 2$ & T3 & $\mathrm{T} 2$ & T3 \\
\hline $\mathrm{T} 1$ & $.72^{* * *}$ & $.63^{* * *}$ & $.23^{* *}$ & .05 & $.70^{* * *}$ & $.65^{* * *}$ & $.56^{* * *}$ & $.47^{* * *}$ & $.78^{* * *}$ & $.63^{* * *}$ & $.63^{* * *}$ & $.61^{\text {*** }}$ \\
\hline $\mathrm{T} 2$ & - & $.78^{* * *}$ & - & $.28^{* * *}$ & - & $.67^{* * *}$ & - & $.56^{* * *}$ & - & $.83^{* * *}$ & - & $.53^{* * *}$ \\
\hline
\end{tabular}

Note. $\mathrm{EPB}=$ Externalizing problem behavior, $\mathrm{ALP}=$ Absolute level of parenting, $\mathrm{PDT}=$ Parental differential treatment, $\mathrm{PSE}=$ Parental self-efficacy.

$\dagger p<.10 .{ }^{*} p<.05 .{ }^{* *} p<.01 .^{* * *} p<.001$.

EPB. At Level 2, the effect of mothers' parenting was only evident for the SCBE-30. When incorporated separately, the effect of ALP was only present for the intercept $(\gamma=-6.83, p<.10)$ but not for the slope. An increase of $1 S D$ in ALP indicated a fall of .20 of a $S D$ in the baseline level of EPB. The effect of PDT was present both on the intercept ( $\gamma=$ $-7.44, p<.05)$ and on the slope $(\gamma=-2.45, p<.05)$. An increase of $1 S D$ in PDT was linked to a fall of .23 of a SD in the baseline level of EPB and to a decrease of .08 of a $S D$ over a 1-year interval. When both parenting measures were included in the model, along with their interaction terms, their main effects were no longer significant, but their interactions were present both on the intercept $(\gamma=14.48$, $p<.10)$ and on the slope $(\gamma=-12.47, p<.05)$. Surprisingly, the results indicate that the effect of PDT on EPB was stronger when ALP was high (see Fig. 1a). Fig. 1 will be considered further in the discussion section.

For the fathers (Table 5), results for the Level 1 predictors indicated that changes in ALP (but not changes in PDT) were associated with changes in EPB $(\gamma=-4.46, p<.10)$, as assessed by the SCBE-30. The marginally significant result for ALP indicates that a $1 S D$ positive change in father ALP in a 1-year interval was associated

Table 3

Results of HLM unconditional growth models: estimates of the intercepts, linear change, and variance in the children's externalizing problem behavior.

\begin{tabular}{|c|c|c|c|c|}
\hline & \multicolumn{3}{|c|}{ Fixed effects } & \multirow{2}{*}{$\begin{array}{l}\text { Random effects } \\
\text { variance }\end{array}$} \\
\hline & Coefficient & SE & $\mathrm{t}(118)$ & \\
\hline \multicolumn{5}{|c|}{ Children's EPB (SCBE-30) } \\
\hline Intercept & 52.460 & 1.649 & $27.26^{* * *}$ & $201.088^{* * *}$ \\
\hline Slope & -2.577 & .687 & $3.75^{* * * *}$ & $20.861^{* * * *}$ \\
\hline Deviance & 2265.69 & & & \\
\hline \multicolumn{5}{|c|}{ Children's EPB (SNAP-game) } \\
\hline Intercept & 2.168 & .047 & $46.37^{* * *}$ & .052 \\
\hline Slope & -.003 & .023 & -.13 & $.012^{*}$ \\
\hline Deviance & 161.40 & & & \\
\hline
\end{tabular}

Note. $N=119$. EPB = Externalizing problem behavior.

${ }^{*} p<.05 .{ }^{* *} p<.01 .{ }^{* * *} p<.001$. with a decrease of 14 of a SD in EPB. However, once changes in both ALP and PDT were included in the model, the ALP effect was no longer significant. For the SNAP-game, results indicated that neither changes in ALP nor changes in PDT were associated with changes in EPB. At Level 2, the results indicated that only ALP was associated with EPB and that the effect of ALP was different for the two outcomes. For the SCBE-30, the effect was on the intercept $(\gamma=-9.49, p<.05)$ and indicates that an increase of $1 S D$ in ALP was associated with a decrease of 30 of a SD in the baseline level of EPB. For the SNAP-game, ALP predicted the slope of EPB, with $\gamma=-.05, p<.05$, indicating that a $1 S D$ increase of ALP was associated with a decrease of .08 of a $S D$ in EPB over a 1-year interval. Although the main effect of father PDT did not predict EPB at all, a PDT $\times$ ALP interaction was significant for the SCBE-30 and did predict EPB trajectories (slope, $\gamma=-5.38$, $p<.05)$. Fig. 1b presents this interaction which will be discussed below.

The second set of models examined the effect of PSE and child personality in predicting changes in EPB, over and above the effects of the level-of, and change-in, ALP (Table 6). The effect of PSE was only demonstrated for the mothers. Mothers' PSE had a consistent effect on the slope of EPB for both the SCBE-30 $(\gamma=-5.38, p<.05)$ and the SNAP-game $(\gamma=-.44, p<.10)$. For a difference of $1 S D$ in mothers' PSE, EPB decreased over a 1-year interval by .16 of a SD for the SCBE30 and .07 SD for the SNAP-game.

As expected, main effects of personality were found, with higher levels of agreeableness (AGR) and conscientiousness (CON) associated with lower levels of EPB on the SCBE-30. The effect of agreeableness was also significant on the slope (for the mothers) but, surprisingly, was positive $(\gamma=1.12, p<.05)$, indicating that an increase of $1 S D$ in agreeableness predicted a deterioration of .08 SD in EPB over a 1-year interval. Follow-up analysis revealed that children who scored higher on agreeableness remained better adapted than less-agreeable children across the three waves of data collection, despite having slower improvement. It may be hypothesized that, as agreeable children begin at a better adjusted level, they are less likely to improve compared to less-agreeable children. A main effect of conscientiousness on the slope of EPB as measured by the SCBE- 30 was also found, with a negative 
Table 4

Results of HLM conditional models of mothers' ALP and PDT predicting change in children's externalizing problem behavior.

\begin{tabular}{|c|c|c|c|c|c|c|}
\hline & \multicolumn{3}{|c|}{ Changes in children's EPB (SCBE-30) } & \multicolumn{3}{|c|}{ Changes in children's EPB (SNAP-game) } \\
\hline & ALP only ${ }^{a}$ & PDT only ${ }^{\mathrm{b}}$ & ALP and PDT ${ }^{c}$ & ALP only ${ }^{a}$ & PDT only ${ }^{b}$ & ALP and PDT ${ }^{c}$ \\
\hline \multicolumn{7}{|l|}{ Fixed effects } \\
\hline \multicolumn{7}{|c|}{ Level 1 time-varying covariates } \\
\hline Changes in ALP & $-4.396(2.681) \dagger$ & & $-3.541(3.124)$ & $.051(.103)$ & & $.135(.115)$ \\
\hline Changes in PDT & & $-.777(1.917)$ & $.971(2.119)$ & & $-.135(.082) \dagger$ & $-.181(.080)^{*}$ \\
\hline \multicolumn{7}{|l|}{ Level 2 intercept } \\
\hline Intercept & $51.960(1.624)^{* * *}$ & $52.405(1.785)^{* * *}$ & $52.463(1.752)^{* * *}$ & $2.173(.047)^{* * *}$ & $2.201(.052)^{* * *}$ & $2.210(.049)^{* * *}$ \\
\hline Mean ALP & $-6.831(4.228) \dagger$ & & $-4.099(4.269)$ & & & \\
\hline Mean PDT & & $-7.437(3.658)^{*}$ & $3.450(3.363)$ & & & \\
\hline $\mathrm{ALP} \times \mathrm{PDT}$ & & & $14.475(7.574) \dagger$ & & & \\
\hline \multicolumn{7}{|l|}{ Level 2 slope } \\
\hline Intercept & $-2.248(0.696)^{* *}$ & $-2.303(.744)^{* *}$ & $-2.480(.746)^{* *}$ & $-.005(.023)$ & $-.001(.025)$ & $-.003(.024)$ \\
\hline Mean ALP & $-1.204(2.016)$ & & -1.664 (1.999) & $-.035(.031)$ & & $-.033(.042)$ \\
\hline Mean PDT & & $-2.448(1.079)^{*}$ & $.383(1.603)$ & & $.024(.024)$ & $-.004(.032)$ \\
\hline ALP $\times$ PDT & & & $-12.472(4.927)^{*}$ & & & $.099(.117)$ \\
\hline
\end{tabular}

Note. $\mathrm{EPB}=$ Externalizing problem behavior, ALP = Absolute level of parenting, PDT = Parental differential treatment.

${ }^{\mathrm{a}} \mathrm{N}=119 ;{ }^{\mathrm{b}} \mathrm{N}=86 ;{ }^{\mathrm{c}} \mathrm{N}=86$.

$\dagger p<.10 .^{*} p<.05 .^{* *} p<.01 .^{* * *} p<.001$

value indicating that greater conscientiousness was associated with a decrease in EPB over time. No main effect of personality was found for EPB as measured by the SNAP-game.

Interactions between ALP and agreeableness were found for both parents. The father ALP $\times$ agreeableness interaction was evident for the SCBE-30 on both the intercept $(\gamma=-4.56, p<.10)$ and the slope

(a) Mothers

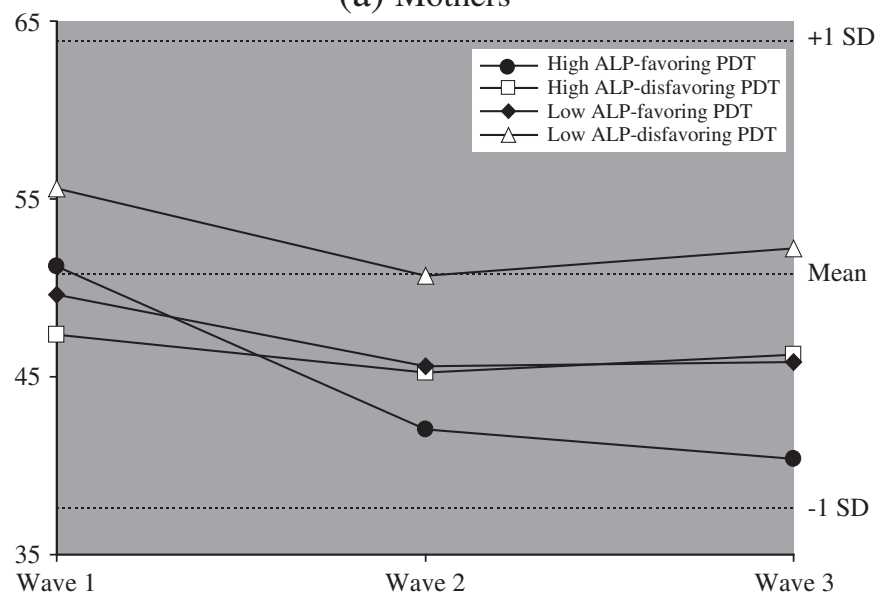

(b) Fathers

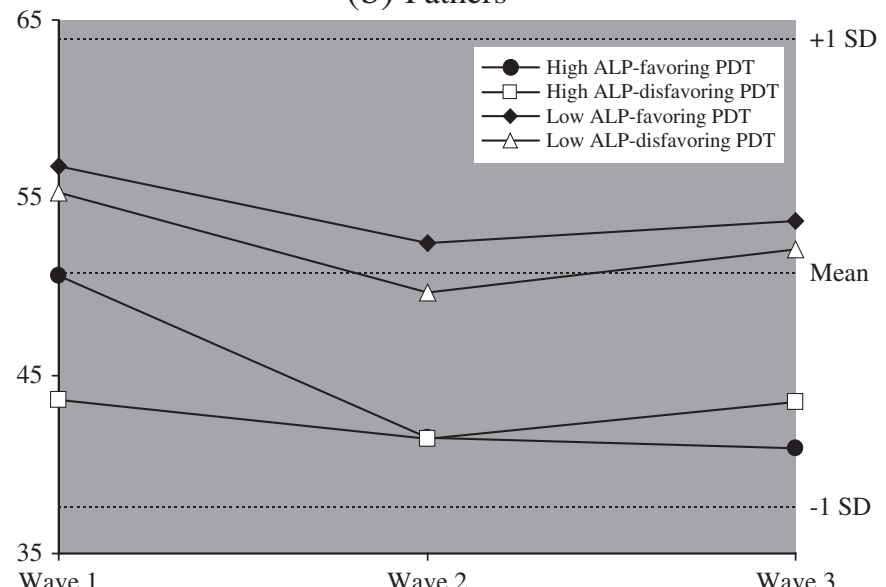

Fig. 1. The interaction of ALP and PDT in predicting the level-of and change-in EPB as assessed by the SCBE-30. (a) Mothers, (b) Fathers.
( $\gamma=1.88, p<.10$ ), but these effects were only marginally significant. Follow-up analysis revealed that more agreeable children showed similar small improvements in EPB regardless of their fathers' ALP level, but those who experienced more negative parenting showed higher EPB at the beginning of the study. Less agreeable children had similar high levels of EPB at the beginning, but the EPB of those experiencing more positive father ALP decreased faster over time. An interaction between mother ALP and agreeableness was also found for the SNAP-game $(\gamma=-.51, p<.05)$. Follow-up analysis revealed that the effect of negative mother ALP was more deleterious over time for children low in agreeableness.

The third set of models examined the effect of parental selfefficacy, child personality and sibling relationships in predicting changes in EPB, over and above the effects of the level and change in PDT (Table 7). The main effects of the parental measures (ALP, PDT and PSE) were similar to those previously found. The main effect of personality on the intercept for the SCBE-30 scores also remained relatively stable, although, predictions on the slope were no longer significant. Conversely, predictions on the SNAP-game showed other patterns of personality prediction, with extraversion (EXT) $(\gamma=.03$, $p<.05)$ and openness (OPE) $(\gamma=.02, p<.05)$ predicting increases in EPB over time. These effects were nonetheless moderate (increases of only .07 to $.09 S D$ in EPB per year) and were close to the .05 significance level.

Significant interactions between the effects of PDT and personality on the intercept of the SCBE-30 score were found for emotional stability (EMS) for both parents ( $\gamma=-8.71, p<.05$ for the mothers and $\gamma=-6.63, p<.10$ for the fathers); the effect of the interaction between PDT and extraversion on the slope was also significant, but only for fathers $(\gamma=1.95, p<.10)$. Follow-up analyses show that children low on emotional stability displayed higher levels of overall EPB compared to other children, and were even less well adapted when encountering disfavoring PDT, whereas the reverse pattern was found for children high on emotional stability. At the same time, children low on extraversion were more sensitive to paternal PDT, displaying higher increases in EPB than highly extraverted children when they were disfavored. For the SNAP-game, there were significant interaction effects on the slope of EPB between mother PDT and emotional stability $(\gamma=.05, p<.10)$ and between father PDT and agreeableness ( $\gamma=.04, p<.05)$. Overall, follow-up analysis revealed that children scoring low on the personality traits displayed higher increases in EPB than children scoring high if they were disfavored.

Finally, sibling relationships (SR) had a significant effect on the intercept of the SCBE-30 ( $\gamma$ ranging between -8.98 and -9.39 , 
Table 5

Results of HLM conditional models of fathers' ALP and PDT predicting change in children's externalizing problem behavior.

\begin{tabular}{|c|c|c|c|c|c|c|}
\hline & \multicolumn{3}{|c|}{ Changes in children's EPB (SCBE-30) } & \multicolumn{3}{|c|}{ Changes in children's EPB (SNAP-game) } \\
\hline & ALP only ${ }^{\mathrm{a}}$ & PDT only ${ }^{b}$ & ALP and PDT ${ }^{c}$ & ALP only ${ }^{a}$ & PDT only ${ }^{b}$ & ALP and PDT \\
\hline \multicolumn{7}{|l|}{ Fixed effects } \\
\hline \multicolumn{7}{|c|}{ Level 1 time-varying covariates } \\
\hline Changes in ALP & $-4.460(2.601) \dagger$ & & $-3.944(3.142)$ & $-.018(.105)$ & & $-.030(.128)$ \\
\hline Changes in PDT & & $-1.393(1.596)$ & $-.215(1.602)$ & & $-.109(.093)$ & $-.128(.096)$ \\
\hline \multicolumn{7}{|l|}{ Level 2 intercept } \\
\hline Intercept & $52.037(1.642)^{* * *}$ & $52.404(1.813)^{* * * *}$ & $52.231(1.781)^{* * *}$ & $2.165(.046)^{* * *}$ & $2.194(.053)^{* * *}$ & $2.189(.051)^{* * *}$ \\
\hline Mean ALP & $-9.802(3.414)^{* *}$ & & $-9.487(3.813)^{*}$ & & & \\
\hline Mean PDT & & $.791(4.105)$ & $-1.491(4.109)$ & & & \\
\hline $\mathrm{ALP} \times \mathrm{PDT}$ & & & $4.156(5.921)$ & & & \\
\hline \multicolumn{7}{|l|}{ Level 2 slope } \\
\hline Intercept & $-2.326(.711)^{* *}$ & $-2.311(.766)^{* *}$ & $-2.247(.773)^{* *}$ & $.0001(.023)$ & $.003(.025)$ & $.006(.025)$ \\
\hline Mean ALP & $.207(1.415)$ & & $-.202(1.483)$ & $-.051(.020)^{* *}$ & & $-.047(.021)^{*}$ \\
\hline Mean PDT & & $-.468(1.772)$ & $1.972(1.805)$ & & $-.004(.023)$ & $-.014(.032)$ \\
\hline $\mathrm{ALP} \times \mathrm{PDT}$ & & & $-5.378(2.527)^{*}$ & & & $.038(.041)$ \\
\hline
\end{tabular}

Note. $\mathrm{EPB}=$ Externalizing problem behavior, $\mathrm{ALP}=$ Absolute level of parenting, $\mathrm{PDT}=$ Parental differential treatment.

${ }^{\mathrm{a}} \mathrm{N}=119 ;{ }^{\mathrm{b}} \mathrm{N}=86 ;{ }^{\mathrm{c}} \mathrm{N}=86$.

$\dagger p<.10{ }^{*} p<.05 .{ }^{* *} p<.01 .^{* * *} p<.001$.

$p<.05$ ), indicating that children who have a better relationship with their sibling also displayed less EPB. The interaction between father PDT and sibling relationships also had a significant effect on the intercept $(\gamma=9.43, p<.05)$. Follow-up analyses revealed that children having poor relationships with their sibling, displayed higher average levels of EPB compared to other children and were even less well adapted in the face of disfavoring PDT, whereas the reverse was observed for children having good sibling relationships.

\section{Discussion}

Using a multi-informant strategy in a 2-year multi-level longitudinal design, we explored how factors across the child, parenting and family domains may predict the developmental course of externalizing problem behavior (EPB) in early childhood. The predictors under investigation included absolute levels of parenting (ALP) and parental differential treatment (PDT), parental self-efficacy (PSE), child personality and sibling relationships, where special attention was

Table 6

Results of HLM conditional models of parents' ALP and additional variables predicting change in children's externalizing problem behavior.

\begin{tabular}{|c|c|c|c|c|}
\hline \multirow[b]{2}{*}{ Fixed effects } & \multicolumn{2}{|c|}{ Changes in children's EPB (SCBE-30) } & \multicolumn{2}{|c|}{ Changes in children's EPB (SNAP-game) } \\
\hline & 1. Mothers & 2. Fathers & 3. Mothers & 4. Fathers \\
\hline \multicolumn{5}{|c|}{ Level 1 Time-varying covariate } \\
\hline ALP & $-4.057(2.679) \dagger$ & $-4.684(2.608) \dagger$ & $.055(.102)$ & $-.028(.109)$ \\
\hline \multicolumn{5}{|l|}{ Level 2 intercept } \\
\hline Intercept & $51.230(1.743)^{* * *}$ & $51.570(1.650)^{* * *}$ & $2.184(.046)^{* * *}$ & $2.174(.045)^{* * *}$ \\
\hline Mean ALP & $-2.714(4.514)$ & $-8.100(4.109)^{*}$ & & \\
\hline Parents' PSE & $-1.650(4.895)$ & $-3.221(4.329)$ & & \\
\hline a. EXT & $-1.442(1.486)$ & $-.691(1.503)$ & & \\
\hline $\mathrm{ALP} \times \mathrm{EXT}$ & $-3.382(4.377)$ & $-1.571(3.005)$ & & \\
\hline b. AGR & $-7.208(1.254)^{* * *}$ & $-6.687(1.235)^{* * *}$ & & \\
\hline $\mathrm{ALP} \times \mathrm{AGR}$ & $-2.163(3.239)$ & $-4.564(2.693) \dagger$ & & \\
\hline c. $\mathrm{CON}$ & $.034(1.077)$ & $.600(1.010)$ & & \\
\hline $\mathrm{ALP} \times \mathrm{CON}$ & $.339(3.264)$ & $-3.371(2.564)$ & & \\
\hline d. EMS & $-4.869(1.602)^{* * *}$ & $-4.523(1.447)^{* *}$ & & \\
\hline ALP $\times$ EMS & $-3.885(4.397)$ & $-3.503(3.417)$ & & \\
\hline e. OP & $-.437(1.749)$ & $-.130(1.601)$ & & \\
\hline $\mathrm{ALP} \times \mathrm{OP}$ & $.001(5.642)$ & $-2.359(3.918)$ & & \\
\hline \multicolumn{5}{|l|}{ Level 2 slope } \\
\hline Intercept & $-2.039(.760)^{* *}$ & $-2.416(.702)^{* * *}$ & $-.008(.023)$ & $-.003(.023)$ \\
\hline Mean ALP & $-.034(2.203)$ & $.363(1.804)$ & $-.024(.035)$ & $-.051(.023)^{*}$ \\
\hline Parents' PSE & $-5.378(2.414)^{*}$ & $.197(1.624)$ & $-.044(.028) \dagger$ & $-.007(.032)$ \\
\hline a. EXT & $-.708(.631)$ & $.461(.739)$ & $.001(.012)$ & $.006(.014)$ \\
\hline $\mathrm{ALP} \times \mathrm{EXT}$ & $-.325(2.463)$ & $1.252(1.101)$ & $-.009(.035)$ & $-.018(.017)$ \\
\hline b. AGR & $1.119(0.556)^{*}$ & $.671(.568)$ & $.008(.009)$ & $.008(.009)$ \\
\hline $\mathrm{ALP} \times \mathrm{AGR}$ & $-.717(1.450)$ & $1.880(1.103) \dagger$ & $-.051(.026)^{*}$ & $-.017(.015)$ \\
\hline c. $\mathrm{CON}$ & $-.725(.422) \dagger$ & $-1.008(.441)^{*}$ & $.008(.008)$ & $.006(.008)$ \\
\hline $\mathrm{ALP} \times \mathrm{CON}$ & $-.070(1.654)$ & $1.027(1.167)$ & $-.017(.023)$ & $.001(.015)$ \\
\hline d. EMS & $-.129(.700)$ & $-.404(.699)$ & $.008(.010)$ & $.006(.010)$ \\
\hline ALP $\times$ EMS & $2.284(1.978)$ & $1.686(1.465)$ & $-.022(.028)$ & $-.003(.015)$ \\
\hline e. $\mathrm{OP}$ & $-.263(.670)$ & $-.439(.669)$ & $.008(.011)$ & $.009(.011)$ \\
\hline $\mathrm{ALP} \times \mathrm{OP}$ & $1.415(2.836)$ & $2.568(1.691)$ & $.019(.037)$ & $-.018(.022)$ \\
\hline
\end{tabular}

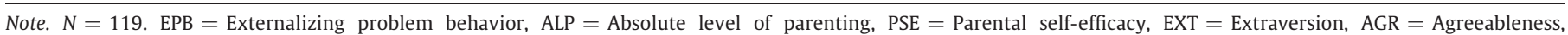
$\mathrm{CON}=$ Conscientiousness, EMS $=$ Emotional stability, OP $=$ Openness.

$\dagger p<.10$. $^{*} p<.05 .^{* *} p<.01$. $^{* * *} p<.001$. 
Table 7

Results of HLM conditional models of parents' PDT and additional variables predicting change in children's externalizing problem behavior.

\begin{tabular}{|c|c|c|c|c|}
\hline \multirow[b]{2}{*}{ Fixed effects } & \multicolumn{2}{|c|}{ Changes in children's EPB (SCBE-30) } & \multicolumn{2}{|c|}{ Changes in children's EPB (SNAP-game) } \\
\hline & 1. Mothers & 2. Fathers & 3. Mothers & 4. Fathers \\
\hline \multicolumn{5}{|c|}{ Level 1 Time-varying covariates } \\
\hline PDT & $-.894(2.145)$ & $-1.542(1.608)$ & $-.133(.082) \dagger$ & $-.103(.088)$ \\
\hline \multicolumn{5}{|l|}{ Level 2 intercept } \\
\hline Intercept & $52.220(1.718)^{* * *}$ & $52.271(1.845)^{* * *}$ & $2.198(.052)^{* * *}$ & $2.193(.052)^{* * *}$ \\
\hline Mean PDT & $2.274(3.819)$ & $1.926(4.352)$ & & \\
\hline Parents' PSE & $.197(5.832)$ & $-4.479(4.203)$ & & \\
\hline a. EXT & $.946(1.629)$ & $.794(1.823)$ & & \\
\hline $\mathrm{PDT} \times \mathrm{EXT}$ & $5.173(3.590)$ & $2.048(2.686)$ & & \\
\hline b. AGR & $-6.182(1.388)^{* * *}$ & $-6.547(1.411)^{* * *}$ & & \\
\hline $\mathrm{PDT} \times \mathrm{AGR}$ & $1.863(1.937)$ & $.405(2.502)$ & & \\
\hline c. $\mathrm{CON}$ & $-.133(1.265)$ & $.134(1.242)$ & & \\
\hline $\mathrm{PDT} \times \mathrm{CON}$ & $-.999(4.162)$ & $-1.336(2.698)$ & & \\
\hline d. EMS & $-4.073(1.821)^{*}$ & $-3.856(1.823)^{*}$ & & \\
\hline PDT $\times$ EMS & $-8.706(4.606)^{*}$ & $-6.626(3.818) \dagger$ & & \\
\hline e. OP & $.007(1.706)$ & $-.273(1.862)$ & & \\
\hline $\mathrm{PDT} \times \mathrm{OP}$ & $-1.645(4.374)$ & $1.939(5.473)$ & & \\
\hline f. SR & $-9.394(4.069)^{*}$ & $-8.981(3.702)^{*}$ & & \\
\hline $\mathrm{PDT} \times \mathrm{SR}$ & $-3.49(3.714)$ & $9.432(4.430)^{*}$ & & \\
\hline \multicolumn{5}{|l|}{ Level 2 slope } \\
\hline Intercept & $-2.404(.799)^{* *}$ & $-2.220(.785)^{* * * *}$ & $.001(.025)$ & $.006(.026)$ \\
\hline Mean PDT & $-3.888(2.093) \dagger$ & $-.202(1.739)$ & $.039(.031)$ & $.008(.026)$ \\
\hline Parents' PSE & $-7.0321(2.885)^{*}$ & $-.801(1.604)$ & $-.056(.031) \dagger$ & $-.045(.028)$ \\
\hline a. EXT & $-.600(.784)$ & $-.141(.876)$ & $.025(.012)^{*}$ & $.024(.012) *$ \\
\hline PDT $\times$ EXT & $.587(2.012$ & $1.945(.985) \dagger$ & $-.022(.028)$ & $.002(.015)$ \\
\hline b. AGR & $.190(.617)$ & $.524(.623)$ & $.013(.009)$ & $.013(.009)$ \\
\hline $\mathrm{PDT} \times \mathrm{AGR}$ & $-1.076(.956)$ & $1.224(1.158)$ & $.001(.015)$ & $.036(.017)^{*}$ \\
\hline c. $\mathrm{CON}$ & $-.551(.537)$ & $-.672(.543)$ & $.006(.007)$ & $.003(.007)$ \\
\hline $\mathrm{PDT} \times \mathrm{CON}$ & $-.382(2.212)$ & $-1.393(1.326)$ & $-.010(.027)$ & $.017(.024)$ \\
\hline d. EMS & $-.399(.810)$ & $-.571(.852)$ & $.006(.010)$ & $.007(.010)$ \\
\hline PDT $\times$ EMS & $1.561(1.805)$ & $.349(1.673)$ & $.045(.026) \dagger$ & $.016(.027)$ \\
\hline e. OP & $-.627(.687)$ & $-.598(.760)$ & $.019(.011) \dagger$ & $.018(.010) \dagger$ \\
\hline $\mathrm{PDT} \times \mathrm{OP}$ & $-.066(1.604)$ & $.218(2.477)$ & $-.033(.031)$ & $-.018(.035)$ \\
\hline f. SR & $-1.372(1.310)$ & $-.202(1.486)$ & $.001(.026)$ & $-.006(.023)$ \\
\hline $\mathrm{PDT} \times \mathrm{SR}$ & $-.896(1.445)$ & $-1.038(2.429)$ & $-.029(.028)$ & $.020(.026)$ \\
\hline
\end{tabular}

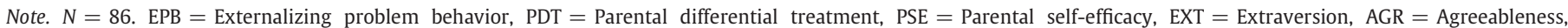
$\mathrm{CON}=$ Conscientiousness, EMS $=$ Emotional stability, OP $=$ Openness, $\mathrm{SR}=$ Sibling relationships.

$\dagger p<.10 .{ }^{*} p<.05 .{ }^{* *} p<.01 .{ }^{* * *} p<.001$.

paid to cross-domain interactive effects. In the light of recent research findings, both the level and the rate of change of parenting were of interest. To our knowledge, this is the only study that has investigated such patterns of relationships with mothers and fathers.

Preliminary analyses revealed that the children from our sample received more support than negative control from their parents, but were, at the same time, somewhat disfavored compared to their closest-in-age sibling. As parents participated in the study on a voluntary basis, it could be argued that they were concerned about their child's development and were, therefore, minded to adopt parenting behavior thought to be positive for their child. However, because "hard-to-manage" children are known to elicit more negative parenting than their normally developing sibling, it seems logical that they will, on average, be the disfavored sibling. Also, associations between mother and father parental measures corroborate previous findings that parents often have similar parenting strategies within families (Coley et al., 2008). However, associations between one parent's ALP and the other parent's PDT were unexpected and may indicate some compensatory process. Indeed, results suggested that a parent will provide more positive parenting to a child who is disfavored by the other parent. Although not central to the goal of the present paper, these results raise some questions surrounding the way parents influence each other in the rearing of their children. Finally, both of the repeated parental measures, ALP and PDT, were highly stable over the period of the study. ALP has previously demonstrated stability over time in the early childhood period (Larsson et al., 2008), but our stability indicator for PDT was relatively high compared to that in other studies (on average .30 in Richmond et al., 2005). This may be explained in that "hard to manage" children are recognized to elicit more PDT-consistently over time-than normally developing children (Kowal et al., 2002).

EPB trajectories: parents' rating vs. observation

Parent ratings and observations have both been recognized to be valuable assessment methods and are thought to be complimentary, as they assess different facets of an underlying behavioral disposition (Epstein, 1983). In this respect, the two assessment methods used in the present study displayed some marked differences worth noting, regarding their convergent validity as well as their stability and rate of change over time.

The convergent validity between the two EPB measures was modest but nonetheless in accord with previous findings (Hughes et al., 2002). Previous findings suggested that parents' reports, although valuable, may be biased based upon personal factors (e.g., depression, Hay et al., 1999) and by past experiences with the child (Patterson, 1982), whereas an observational approach is thought to offer a-less biased-ecologically valid alternative. Also, whereas the SNAP paradigm assesses disruptive behavior in a highly specific context at a specific time, questionnaires such as the SCBE-30 provide global ratings of everyday behavior across a wide range of contexts and a large time frame. Finally, the constructs under investigation (anger, aggressiveness, opposition for the SCBE-30; aggression, negative affect and arousal for the SNAP-game), both belong to the externalizing spectrum but are somewhat different.

The above mentioned factors, may also partially explain the differences in stability and change over time across the two EPB 
measures. More specifically, the unexpected moderate stability of the SNAP-game may be due to the highly specific nature of the context and time in which the observations took place. As previously noted, the SNAP paradigm provides a valuable window into children's disruptive behavior in a highly salient context (Hughes et al., 2002). However, although the variability of the context had been partially controlled for by the standardized format of the competitive game, the partner effects could not be controlled as children chose a classmate for whom we had no behavioral screening.

Finally, results indicate that change in EPB as assessed by the parents (SCBE-30) fell at a rate of .20 SD per year which supports the expectation that children's EPB generally decreases in the preschool period (Day, Peterson, \& McCracken, 1998). Conversely, the results for the SNAP-game indicated no significant change in EPB over time. It may be, for example, that parents assessed externalizing behavior more on the basis of parent-child conflictual situations (e.g., opposition, lack of compliance) than on the basis of peer-to-peer interactions (e.g., agitation, arousal). In this respect, parents may see signs of progress in adjustment because of better child compliance while at the same time he or she is still disruptive when playing with peers. Another explanation may be that the SNAP-game taps partially on temperamental reactivity-more specifically on frustration reactivity-which is thought to be stable over time (Eisenberg et al., 2000). Theoretically speaking, frustration reactivity is related to disruptive behavior, though the former is an emotional excitation whereas the latter is a behavioral manifestation. Although somewhat stable, frustration reactivity is influenced by the growing emotional regulation capabilities that children acquire which leads to a decline in disruptive behavior over time (Denham \& Burton, 1996). Although the SNAP-game has demonstrated evidence of its ecological and construct validity in assessing disruptive behavior (Hughes et al., 2002), we must acknowledge that it has not previously been related to temporal reactivity nor emotional regulational processes.

\section{Predictors of EBP trajectories}

Overall our results confirmed that the level-of and change-in ALP and PDT are of interest when explaining the developmental trajectories of EPB. The results showed different patterns for mothers and fathers, and for the two methods of measuring EPB. In general, children were sensitive to both mother ALP and PDT, but only to father ALP. Because mothers tend to be more sensitive than fathers (Acock \& Demo, 1994), and because children may be more sensitive to differences in support than to differences in negative control (Meunier \& Roskam, 2009a), our results are quite logical. Moreover, this is in accord with the idea that maternal parenting is more predictive of child EPB than paternal parenting (Aunola \& Nurmi, 2005).

Although the main effect of PDT was not significant for the fathers, its interactive effect with ALP was consistent for the two parents for the SCBE-30. As Fig. 1 shows, the EPB trajectories were more favorable when children experienced both high levels of ALP and favoring (or less disfavoring) PDT. However, the results also showed that disfavored children had worse trajectories when experiencing higher ALP (as compared to children experiencing lower ALP). This was contrary to previous findings suggesting that children tend to be more sensitive to differential treatment when they also experience negative ALP (Feinberg \& Hetherington, 2001). However, considering that reciprocal parent-child effects could not be fully controlled in this study and that the specificity of our sample (i.e. clinically referred) may heighten the possibility of child-driven effects, logical explanations for this pattern can be found. As shown in Fig. 1, baseline and average level of EPB was higher for children experiencing lower ALP than for children experiencing higher levels of ALP. Considering the baseline levels of EPB along with the trajectories, it may thus be argued that children displaying higher levels of EPB were less sensitive to disfavoring PDT because differentiated parenting is probably within the range of "normality", given their harder-tomanage behavior. Conversely, children displaying only moderate levels of EPB could be more sensitive to disfavoring PDT even if they experienced a relatively high level of ALP. Although unexpected, our results raise interesting questions regarding a possible baseline level of EPB $\times$ PDT interaction in predicting EPB trajectories. However, further research is needed to corroborate these preliminary findings.

The effects of time-varying covariates were usually marginally significant but they were consistent with the hypotheses. Our results suggest that changes in both parents' ALP could be predictive of EPB trajectories (Burke et al., 2008). In line with previous studies (e.g., Larsson et al., 2008), increasing parenting negativity was shown to worsen EPB as assessed by the parents. The effects of change in PDT were only evident for the mothers and on the observational paradigm. Differentiated effects on the outcome measures suggest that changes in ALP and changes in PDT may affect different aspects of the child externalizing spectrum. From the association between the change of maternal PDT and the SNAP-game, it may be argued that the frustration of being less favored by the mother over time may induce some patterns of behavior which are not directly observed by the parents, but likely to be triggered by the frustration-inducing nature of the SNAP-game. This is even more plausible when considering that both the PDT and the setting of the SNAP-game involved social comparison processes (respectively with the siblings and with a peer).

Although no effect of PSE was found for the fathers, the influence of mothers' PSE on EPB trajectories were consistently demonstrated for the two EPB measures. In line with the social learning framework (Patterson, 1982), it can be argued that children have more opportunity to learn behavioral strategies from their mothers because mothers engage in more frequent interactions with children compared to fathers (Lewis \& Lamb, 2003). It is also important to note that this is the first study that demonstrated the effect of mothers' PSE on EPB trajectories after controlling for parenting behavior variables (ALP \& PDT separately). In this respect, as most of the existing studies have almost exclusively related PSE either to child's behavior or to parental behavior, our results encourage further exploration of complex processes between these three constructs.

As in previous studies, we found a main effect of personality, especially for agreeableness, emotional stability and conscientiousness (Prinzie et al., 2003). In general, the better adapted the personality traits, the lower the baseline EPB and the better the EPB trajectory. The negative impact of agreeableness on the slope was examined in conjunction with its effect on the intercept, and it has been argued that more agreeable children have lower baseline levels of EPB, and therefore less opportunity to experience favorable changes, than less agreeable children. In line with the goodness-offit theory (Thomas \& Chess, 1977), it was hypothesized that children could be differentially influenced by parenting as a function of their personality traits. Our results corroborated the role of agreeableness as a protective factor buffering the effect of mothers' and fathers' negative parenting (ALP) (Van Leeuwen et al., 2004). Although expected, a conscientiousness $\times$ ALP interaction was not demonstrated. Finally, interactions between PDT and personality were demonstrated for emotional stability and agreeableness. More precisely, there was an interaction between PDT and emotional stability on both the intercept (mothers' and fathers' SCBE-30) and the slope (mothers' SNAP-game), and between PDT and agreeableness (slope for fathers' SNAP-game only). Overall, the results demonstrated that children with less well-adapted personality traits were more sensitive to disfavoring PDT compared to children with better adjusted traits. Taken together, the results suggested that children low in agreeableness seemed to be more sensitive to paternal parenting and to ALP. Conversely, children low in emotional stability appeared to be more sensitive to maternal parenting and to PDT.

Finally, our study explored the effect of the relationship with the nearest-in-age sibling in predicting EPB baseline levels and 
trajectories, over and above the effect of both the time-varying and the mean level effect of PDT. Like Kim et al. (2007) but unlike Richmond et al. (2005), we found sibling relationships to be linked to the concurrent level of EPB. No effect of sibling relationships on the slope of EPB was found, which was in accordance with the other two studies. There was an interaction between paternal PDT and sibling relations on the intercept, suggesting that bad sibling relationships predicted higher EPB and that this effect was facilitated by favoring the target child. Although surprising, this result highlighted the possible importance of sibling jealousy in the development of EPB. However, because sibling jealousy was not specifically addressed in the present study, no more precise interpretation can be made. Future research should address a broader range of sibling-relationship dimensions (e.g., jealousy, dominance) from both children, simultaneously with PDT assessment.

\section{Limitations and future directions}

Although this study extended existing research in several ways, it has some limitations and important suggestions for future research. First, the present sample was quite homogeneous both regarding socio-economic indices (working- and middle-class) and origins (mostly Caucasian), and was overselected for EPB. The current results may therefore not be generalizable and should be replicated with other independent-referred and non-referred-samples from diverse cultural and economic groups. Also, although precautions were taken in order to improve statistical power-by using reliable and composite measures with a cross-rater strategy and by reducing risks of multicollinearity (Chaplin, 1991), we must acknowledge that the restricted size of our sample may have limited our ability to find effects, in particular interactions that are recognized to be difficult to detect (McClelland \& Judd, 1993). Second, because the data were collected at three points in time, we could only test linear trajectories, ${ }^{4}$ while change in child EPB is recognized not to be smooth across development (Larsson et al., 2008). Third, the specificity of our methodology (a.o. using time-varying predictors) prevents us to fully control for possible reciprocal effects. These problems may possibly be addressed, for example, by linking each wave's outcomes to prior wave's predictors (Singer \& Willett, 2003). However, it was not possible in our case due to the limited number of assessment waves we had. Fourth, as we based our time prediction on the number of waves, children from three different age groups were confounded in the cohort. As preschool and early childhood is recognized as a period of substantial change in EPB, this may have masked some possible effects. Fifth, because of the complexity of the analyses including numerous predictors, models were considered separately for the mothers and for the fathers. As previous findings suggest that children's outcomes are better understood when both parents are considered (Rothbaum \& Weisz, 1994), future research should benefit from considering multiple parental predictors of child EPB for both mothers and fathers simultaneously. This seems even more important as we found that mothers and fathers-through their reports of ALP, PDT and PSE-have distinct patterns of influence on their child's behavior. Finally, even if the use of an observational paradigm allowed us to avoid sharedmethod variance, our results highlight the importance of refining the SNAP-game. For example, a computerized version of the game could be developed, with a virtual teasing partner, to fully control for partner effects. At the same time, it could be useful to further consider the potential role of the temperamental reactivity in this observational paradigm, to better understand developmental patterns of EPB as assessed in an ecological context.

Despite some limitations, there are important implications of this study for future intervention. Indeed, our findings may encourage

\footnotetext{
${ }^{4}$ At least four assessment waves is needed for testing non-linear trajectories (see Singer \& Willett, 2003, for details).
}

professionals to use multiple assessment methods in order to render a more comprehensive view on EPB across contexts. As mothers, fathers and sibships influence children's psychological adjustment, one may also wish to include the whole family context in order promote positive changes in child development, for example, by reducing parental differential treatment or by enhancing the quality of the sibling relationships. Also, considering the numerous family correlates of parental self-efficacy (see Jones \& Prinz, 2005, for a review) and its considerable importance for the mothers-as noted in the present study-future intervention should move beyond the behavioral factors and further consider this cognitive component of the parental role. Finally, because change in the family context is of great importance, results encourage the consideration of family history and how the relative position of each child could have changed over time. For example, family processes, such as PDT, have been found to increase differences across siblings over time (Johnston, 1996). Taken together, our results encourage others to consider the whole family context-considering multiple members, multiple factors as well as temporality-to provide a holistic picture of family processes which, in turn, may guide interventions for the family members to whom it should be directed.

\section{References}

Acock, A. C., \& Demo, D. H. (1994). Family diversity and well-being. Thousand Oaks, CA: Sage.

Aiken, L., \& West, S. G. (1991). Multiple regression: Testing and interpreting interactions. Newbury Park, CA: Sage.

Aunola, K., \& Nurmi, J. -E. (2005). The role of parenting styles in children's problem behavior. Child Development, 76, 1144-1159.

Bandura, A. (1977). Self-efficacy: Toward a unifying theory of behavioral change Psychological Review, 84, 191-215.

Bank, L., Patterson, G. R., \& Reid, J. B. (1996). Negative sibling interaction patterns as predictor of later adjustment problems in adolescent and young adult males. In G. H. Brody (Ed.), Sibling relationships: Their causes and consequences (pp. 197-229). Westport, CT: Ablex.

Baumrind, D. (1971). Current patterns of parental authority. Developmental Psychology Monographs, 4, 1-103.

Belsky, J., Hsieh, K. -H., \& Crnic, K. (1998). Mothering, fathering, and infant negativity as antecedents of boys' externalizing problems and inhibition at age 3 years: Differential susceptibility to rearing experience? Development and Psychopathology, 10, 301-319.

Boer, F., Westenberg, P., McHale, S., Updegraff, K., \& Stocker, C. (1997). The factorial structure of the Sibling Relationship Inventory (SRI) in American and Dutch Samples. Journal of Social and Personal Relationships, 14, 851-859.

Boyle, M. H., Jenkins, J. M., Georgiades, K., Cairney, J., Duku, E., \& Racine, Y. A. (2004). Differential-maternal parenting behavior: Estimating within and between family effects. Child Development, 75, 1457-1476.

Brody, G. H., Stoneman, Z., \& McCoy, J. (1992). Parental differential treatment of siblings and sibling differences in negative emotionality. Journal of Marriage and Family, 54, 643-651.

Bronfenbrenner, U. (1986). Ecology of the family as a context for human development: Research perspectives. Developmental Psychology, 22, 723-742.

Burke, J., Pardini, D., \& Loeber, R. (2008). Reciprocal relationships between parenting behavior and disruptive psychopathology from childhood through adolescence. Journal of Abnormal Child Psychology, 36, 679-692.

Cabrera, N. J., Shannon, J. D., \& Tamis-LeMonda, C. (2007). Fathers' influence on their children's cognitive and emotional development: From toddlers to pre-K. Applied Developmental Science, 11, 208-213.

Campbell, S. B. (1995). Behavior problems in preschool children: A review of recent research. Journal of Child Psychology and Psychiatry, 36, 113-149.

Chaplin, W. F. (1991). The next generation of moderator research in personality psychology. Journal of Personality and Social Psychology, 59, 143-178.

Coley, R. L., \& Medeiros, B. L. (2007). Reciprocal longitudinal relations between nonresident father involvement and adolescent delinquency. Child Development, 78, $132-147$.

Coley, R. L., Votruba-Drzal, E., \& Schindler, H. (2008). Trajectories of parenting processes and adolescent substance use: Reciprocal effects. Journal of Abnormal Child Psychology, 36, 613-625.

Day, R. D., Peterson, G. W., \& McCracken, C. (1998). Predicting spanking of younger and older children by mothers and fathers. Journal of Marriage and Family, 60, 79-94.

Denham, S., \& Burton, R. (1996). A social-emotional intervention for at-risk 4-yearolds. Journal of School Psychology, 34, 225-245.

Eisenberg, N., Fabes, R. A., Guthrie, I. K., \& Reiser, M. (2000). Dispositional emotionality and regulation: Their role in predicting quality of social functioning. Journal of Personality and Social Psychology, 78, 136-157.

Ekman, P. (1984). Expression and the nature of emotion. In K. R. Scherer \& P. Ekman (Eds.), Approaches to emotion (pp. 319-344). Hillsdale, NJ: Erlbaum. 
Epstein, S. (1983). Aggregation and beyond: Some basic issues in the prediction of behaviour. Journal of Personality and Social Psychology, 51, 360-392.

Feinberg, M. E., \& Hetherington, E. (2001). Differential parenting as a within-family variable. Journal of Family Psychology, 15, 22-37.

Feinberg, M. E., Neiderhiser, J. M., Simmens, S., Reiss, D., \& Hetherington, E. (2000). Sibling comparison of differential parental treatment in adolescence: Gender, selfesteem, and emotionality as mediators of the parenting-adjustment association. Child Development, 71, 1611-1628.

Gadeyne, E., Ghesquière, P., \& Onghena, P. (2004). Longitudinal relations between parenting and child adjustment in young children. Journal of Clinical Child and Adolescent Psychology, 33, 347-358.

Hay, D. F., Pawlby, S., Sharp, D., Shmücker, G., Mills, A., Allen, H., et al. (1999). Parents judgement about young children's problems: Why mothers and fathers might disagree yet still predict later outcomes. Journal of Child Psychology and Psychiatry, $40,1249-1258$

Hetherington, E. M., Henderson, S. H., \& Reiss, J. B. (1999). Adolescent siblings in stepfamilies: Family functioning and adolescent adjustment. Monographs of the Society for Research in Child Development, 64, 1-209.

Hops, H., Davis, B., \& Longoria, N. (1995). Methodological issues in direct observation: Illustrations with the Living in Familial Environments (LIFE) coding system. Journal of Clinical Child Psychology, 24, 193-203.

Hughes, C., Oksanen, H., Taylor, A., Jackson, J., Murray, L., Caspi, A., et al. (2002). 'I'm gonna beat you!' SNAP!: An observational paradigm for assessing young children's disruptive behaviour in competitive play. Journal of Child Psychology and Psychiatry, 43, 507-516

Jenkins, J. M., Dunn, J., O'Connor, T. G., Rasbash, J., \& Behnke, P. (2005). Change in maternal perception of sibling negativity: Within- and between-family influences. Journal of Family Psychology, 19, 533-541.

Johnston, C. (1996). Parent characteristics and parent-child interactions in families of non-problem children and ADHD children with higher and lower levels of oppositional-defiant behavior. Journal of Abnormal Child Psychology, 24, 85-104.

Jones, T. L., \& Prinz, R. J. (2005). Potential roles of parental self-efficacy in parent and child adjustment: A review. Clinical Psychology Review, 25, 341-363.

Kim, J. -Y., MacHale, S. H., Crouter, A. C., \& Osgood, D. (2007). Longitudinal linkages between sibling relationships and adjustment from middle childhood through adolescence. Developmental Psychology, 43, 960-973.

Kochanska, G., Aksan, N., \& Joy, M. E. (2007). Children's fearfulness as a moderator of parenting in early socialization: Two longitudinal studies. Developmental Psychology, 43, 222-237.

Kowal, A. K., Kramer, L., Krull, J. L., \& Crick, N. R. (2002). Children's perceptions of the fairness of parental preferential treatment and their socioemotional well-being. Journal of Family Psychology, 16, 297-306.

LaFrenière, P. J., \& Dumas, J. E. (1996). Social competence and behavior evaluation in children ages 3 to 6 years: The short form (SCBE-30). Psychological Assessment, 8 , $369-377$.

LaFrenière, P. J., Masataka, N., Butovskaya, M., Chen, Q., Dessen, M. A., Atwanger, K., et al (2002). Cross-cultural analysis of social competence and behavior problems in preschoolers. Early Education and Development, 13, 201-220.

Larsson, H., Viding, E., Rijsdijk, F., \& Plomin, R. (2008). Relationships between parental negativity and childhood antisocial behavior over time: A bidirectional effects model in a longitudinal genetically informative design. Journal of Abnormal Child Psychology, 36, 633-645.

Lewis, C. C., \& Lamb, M. E. (2003). Fathers' influences on children's development: The evidence from two-parent families. European Journal of Psychology of Education, 18 $211-228$.

McCartney, K., Burchinal, M. R., \& Bub, K. L. (2006). Best practices in quantitative methods for developmentalists. Monographs of the Society for Research in Child Development, 71.

McClelland, G. H., \& Judd, C. M. (1993). Statistical difficulties of detecting interactions and moderator effects. Psychological Bulletin, 114, 376-390.

McFadyen-Kethum, S., Bates, J., Dodge, K., \& Pettit, G. (1996). Patterns of change in early childhood aggression-disruptive behavior. Child Development, 67, 2417-2433.

McHale, S. M., \& Pawletko, T. (1992). Differential treatment of siblings in two family contexts. Child Development, 63, 68-81.

Measelle, J. R., Ablow, J. C., Cowan, P. A., \& Cowan, C. P. (1998). Assessing young children's views of their academic, social, and emotional lives: An evaluation of the selfperception scales of the Berkeley puppet interview. Child Development, 69, 1556-1576.

Meunier, J. C., \& Roskam, I. (2007). Psychometric properties of a parental childrearing behavior scale for French-speaking parents, children, and adolescents. European Journal of Psychological Assessment, 23, 113-124.

Meunier, J. C., \& Roskam, I. (2009a). Parental differential treatment, child's externalizing behavior and sibling relationships: Bridging links with child's perception of favoritism, personality traits and parent's self-efficacy beliefs. Manuscript in revision for publication.

Meunier, J. C., \& Roskam, I. (2009b). Self-efficacy beliefs amongst parents of young children: Validation of a self-report measure. Journal of Child and Family Studies, 18, 495-511.

Meunier, J. C., Roskam, I., \& Browne, D., T. (in press). Relations between parenting and child's behavior: Exploring child's personality and parental self-efficacy as third variables. International Journal of Behavioral Development.

Patterson, G. R. (1982). Coercive family process. A social interactional approach (Vol. IV). Eugene, OR: Castalia.

Plomin, R., \& Daniels, D. (1987). Why are children in the same family so different from each other? Behavioral Brain Science, 10, 1-16.

Prinzie, P., Onghena, P., Hellinckx, W., Grietens, H., Ghesquière, P., \& Colpin, H. (2003). The additive and interactive effects of parenting and children's personality on externalising behavior. European Journal of Personality, 17, 95-117.

Raudenbush, S. W., Brennan, R. T., \& Barnett, R. C. (1995). A multivariate hierarchical model for studying psychological change within married couples. Journal of Family Psychology, 9, 161-174.

Raudenbush, S. W., \& Bryk, A. S. (2002). Hierarchical linear models: Applications and data analysis methods (2nd ed.). Thousand Oaks, CA: Sage.

Raudenbush, S. W., Bryk, A. S., Cheong, Y. F., \& Congdon, R. (2008). HLM 6.06: Hierarchical linear and nonlinear modeling. Lincolnwood, IL: Scientific Software International.

Richmond, M. K., Stocker, C. M., \& Rienks, S. L. (2005). Longitudinal associations between sibling relationship quality, parental differential treatment, and children's adjustment. Journal of Family Psychology, 19, 550-559.

Roeser, R., Eccles, J., \& Strobel, K. (1998). Linking the study of schooling and mental health: Selected issues and empirical illustrations at the level of the individual. Educational Psychologist, 33, 153-176.

Roskam, I., de Maere-Gaudissart, A., \& Vandenplas-Holper, C. (2000). Mise au point d'un instrument d'évaluation de la personnalité des enfants à partir du Modèle à Cinq Facteurs [Validation of bipolar rating scales based on the Five-Factor Model of personality]. L'Orientation Scolaire et Professionnelle, 29, 661-672.

Roskam, I., Meunier, J. C., Stievenaert, M., \& Van de Moortele, G. (2009). Evidence for a multi informant multi method assessment of preschoolers' behavior. Manuscript submitted for publication.

Rothbaum, F., \& Weisz, J. R. (1994). Parental caregiving and child externalizing behavior in non clinical samples: A meta-analysis. Psychological Bulletin, 116, 55-74.

Sameroff, A. J., Seifer, R., Bartko, W. T., Luthar, S. S., Burack, J. A., Cicchetti, D., et al. (1997). Environmental perspectives on adaptation during childhood and adolescence. In S. S. Luthar, J. A. Burack, D. Cicchetti, \& J. R. Weisz (Eds.), Developmental Psychopathology: Perspectives on adjustment, risk, and disorder (pp. 507-526). New York, NY: Cambridge University Press.

Schaefer, E. S., \& Edgerton, M. (1981). The Sibling Inventory of Behavior. Chapel Hill, NC: University of North Carolina.

Schafer, J. L. (1997). Analysis of incomplete multivariate data. London: Chapman \& Hall.

Scholte, R., Engels, R. C., de Kemp, R. A., Harakeh, Z., \& Overbeek, G. (2007). Differential parental treatment, sibling relationships and delinquency in adolescence. Journal of Youth and Adolescence, 36, 661-671.

Singer, J. D., \& Willett, J. B. (2003). Applied longitudinal data analysis: Modeling change and event occurrence. New York, NY: Oxford University Press.

Sofronoff, K., \& Farbotko, M. (2002). The effectiveness of parent management training to increase self-efficacy in parents of children with Asperger syndrome. Autism, 6, $271-286$.

Tamrouti-Makkink, I. D., Dubas, J. S., Gerris, J. R., \& van Aken, M. A. (2004). The relation between the absolute level of parenting and differential parental treatment with adolescent siblings' adjustment. Journal of Child Psychology and Psychiatry, 45, 1397-1406

Thomas, A., \& Chess, S. (1977). Temperament and Development. New York, NY: Brunner/Mazel.

Turkheimer, E., \& Waldron, M. (2000). Nonshared environment: A theoretical, methodological and quantitative review. Psychological Bulletin, 126, 78-108.

Van der Ende, J., \& Verhulst, F. C. (2005). Informant, gender and age differences in rating of adolescent problem behavior. European Child and Adolescent Psychiatry, 14, 117-126.

Van Leeuwen, K. G., Mervielde, I., Braet, C., \& Bosmans, G. (2004). Child personality and parental behavior as moderators of problem behavior: Variables- and personcentered approaches. Developmental Psychology, 40, 1028-1046.

Van Leeuwen, K. G., \& Vermulst, A. A. (2004). Some psychometric properties of the Ghent Parental Behaviour Scale. European Journal of Psychological Assessment, 20, 283-298.

Volling, B. L., \& Blandon, A. Y. (2005). Positive indicators of sibling relationship quality: The Sibling Inventory of Behavior. In K. A. Moore \& L. H. Lippman (Eds.), What do children need to flourish: Conceptualizing and measuring indicators of positive development (pp. 203-209). New York, NY: Springer Science. 